\title{
Triboelectrochemistry: Influence of Applied Electrical Potentials on Friction and Wear of Lubricated Contacts
}

\author{
Hugh A. Spikes ${ }^{1}$ (D)
}

Received: 22 June 2020 / Accepted: 4 August 2020 / Published online: 14 August 2020

(c) The Author(s) 2020

\begin{abstract}
Research on the effects of applied electrical potential on friction and wear, a topic sometimes termed "Triboelectrochemistry", has been reviewed. Historically, most such research has focussed on aqueous lubricants, whose relatively high electrical conductivities enable use of three-electrode electrochemical kinetic techniques, in which the electrode potential at a single electrode I fluid interface is controlled relative to a suitable reference electrode. This has led to identification of several different mechanisms by which applied electrode potentials can influence friction and wear. Of these, the most practically important are: (i) promotion of adsorption/desorption of polar additives on tribological surfaces by controlling the latters' surface charges; (ii) stimulation or suppression of redox reactions involving either oxygen or lubricant additives at tribological surfaces. In recent years, there has been growing interest in the effects of applied electrical potentials on rubbing contacts lubricated by non-aqueous lubricants, such as ester- and hydrocarbon-based oils. Two different approaches have been used to study this. In one, a DC potential difference in the $\mathrm{mV}$ to $\mathrm{V}$ range is applied directly across a thin film, lubricated contact to form a pair of electrode I fluid interfaces. This has been found to promote some additive reactions and to influence friction and wear. However, little systematic exploration has been reported of the underlying processes and generally the electrode potentials at the interfaces have not been well defined. The second approach is to increase the conductivity of non-aqueous lubricants by adding secondary electrolytes and/or using micro/nanoscale electrodes, to enable the use of three-electrode electrochemical methods at single metal I fluid interfaces, with reference and counter electrodes. A recent development has been the introduction of ionic liquids as both base fluids and lubricant additives. These have relatively high electrical conductivities, allowing control of applied electrode potentials of individual metal I fluid interfaces, again with reference and counter electrodes. The broadening use of "green", aqueous-based lubricants also enlarges the possible future scope of applied electrode potentials in tribology. From research to date, there would appear to be considerable opportunities for using applied electrical potentials both to promote desirable and to supress unwanted lubricant interactions with rubbing surfaces, thereby improving the tribological performance of lubricated machine components.
\end{abstract}

Hugh A. Spikes

h.spikes@imperial.ac.uk

1 Departments of Mechanical Engineering, Imperial College

London, London SW7 2AZ, UK 


\section{Graphical Abstract}
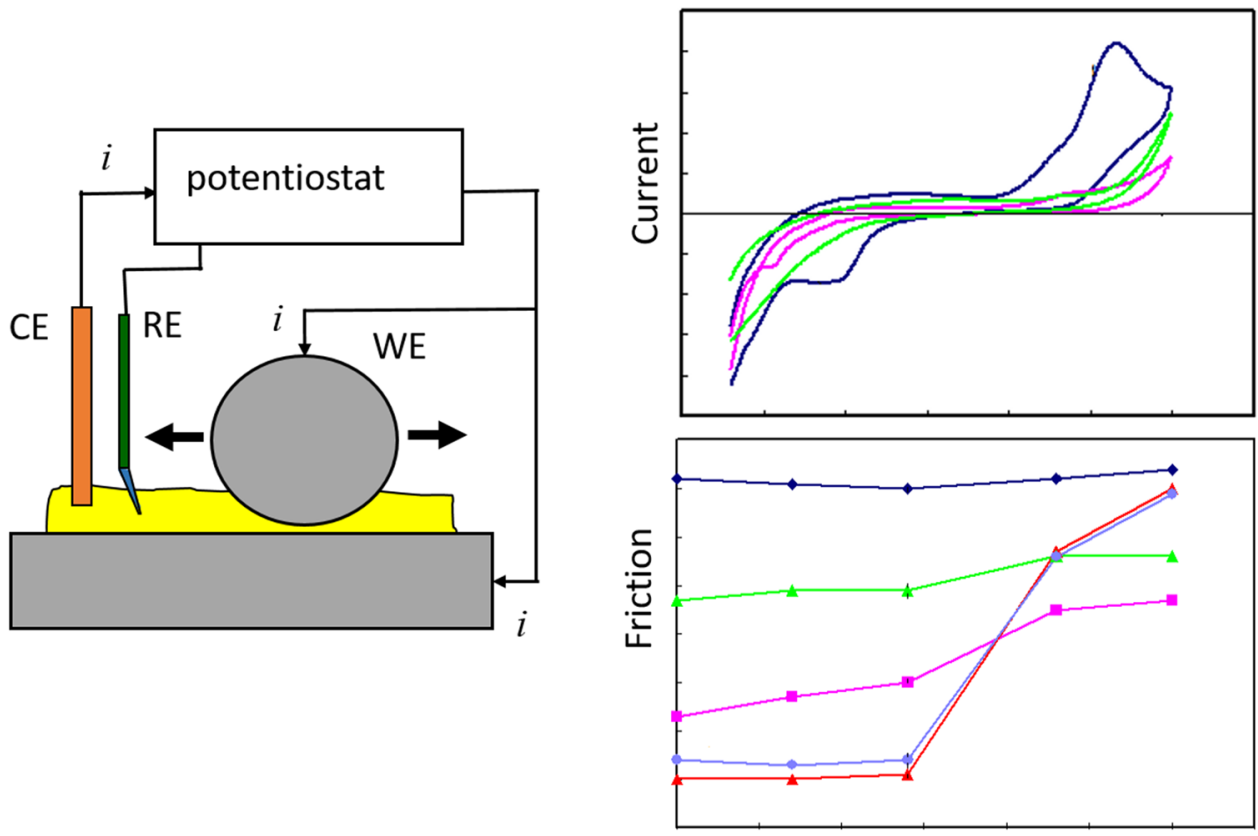

Electrode potential

Keywords Triboelectrochemistry $\cdot$ Friction $\cdot$ Wear $\cdot$ Sliding $\cdot$ Applied voltage $\cdot$ Applied potential $\cdot$ Electrochemistry $\cdot$ Voltammetry $\cdot$ EIS $\cdot$ Tribotronics

\section{Introduction}

In 1874, Thomas Edison applied for a patent on a new type of telegraph receiver [1]. This device which he termed the "electromotograph" [2] was based on the observation that the passage of electricity through the sliding contact between a lead pin and the surface of paper moistened with potassium hydroxide, changed its kinetic friction so that variations in electric field could be converted very rapidly to mechanical motion. Edison thus claimed:

A moving surface in contact with a yielding vibrator, through which pulsations of electricity are passed when such surfaces in contact are of such a character that the friction will be varied by the electrical condition

In subsequent years, many other scientists and engineers have studied the influence of applied electrical potentials on rubbing contacts and shown that quite small potentials can produce significant changes in both friction and wear. However, the literature is very disparate, not least because, as will be described in the next section, electric fields can be applied in various ways to many different tribological systems, so that it is difficult to extract a coherent picture of what has been achieved and how this knowledge can be applied. The aim of this paper is to review past research on the application of electrical potentials to lubricated contacts and to try to extract from this research an understanding of when and how such potentials can change the tribological performance of these contacts.

This review is stimulated in part by the imminent prospect of motor vehicles propelled by internal combustion engines (ICEs) being generally superseded by electric vehicles (EVs) powered by batteries and electric motors (an

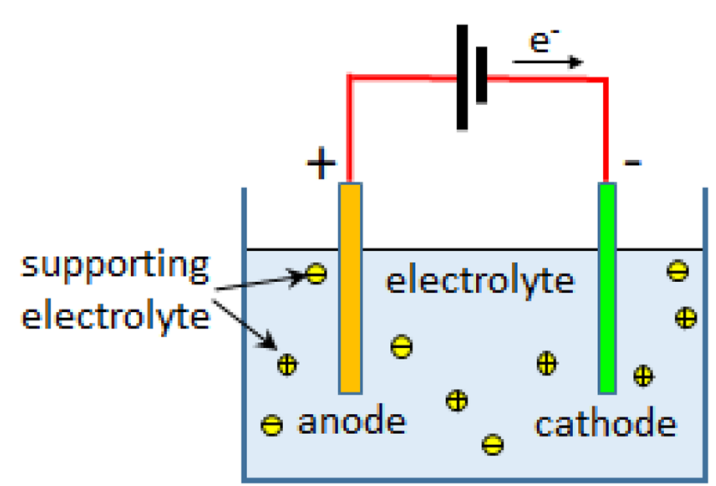

Fig. 1 Schematic diagram of electrolytic cell 
advance predicted somewhat prematurely by Thomas Edison himself in 1902 [3]). The lubricated contacts in EVs are perhaps more likely to be exposed to stray currents than those in ICEs, while the ready availability of electrical energy in EVs provides an opportunity for its use to promote desirable interactions, or to suppress undesirable ones.

The reader will note that historically the bulk of published research has reported the behaviour of lubricants based on aqueous salt solutions, reflecting their high ionic conductivities that enable electrochemical kinetic methods to be applied reliably. However, research on aqueous systems, as well as having direct relevance to water-based lubricants, also provides useful insights into possible effects in nonaqueous lubricants, such as mineral oils. Thus, although the main objective of this review is to summarise electrical effects in organic liquid lubricants, research on aqueous systems is also surveyed.

There have been a few previous reviews of the application of electrical potentials in tribology, usually focussed on a particular aspect of the field. In 1970, Waterhouse outlined electrochemical research on aqueous systems related to tribology, with an emphasis on corrosion [4]. This was followed in 1980 by a more detailed review of research to date by Guruswamy and Bockris, again confined to water-based lubricants and in which the authors first coined the term "Triboelectrochemistry" [5]. In 2012, Lvovich examined the application of electrochemical impedance spectroscopy to study industrial lubricants [6], while in 2015 Xie et al. considered the very wide range of phenomena possible when charged surfaces were generated in lubricated contacts [7]. Very recently, Jiang et al. have considered the impact of electric and magnetic fields on the main lubrication regimes from a primarily mechanistic point of view [8], while Krim has used a series of case study examples to describe how (a)

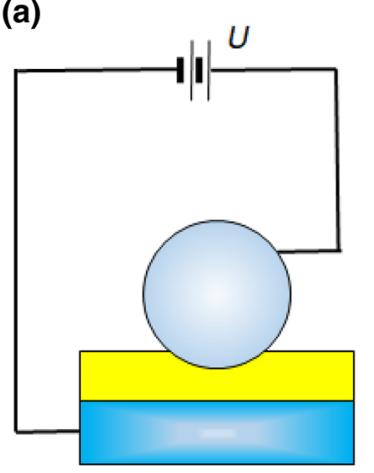

(b)

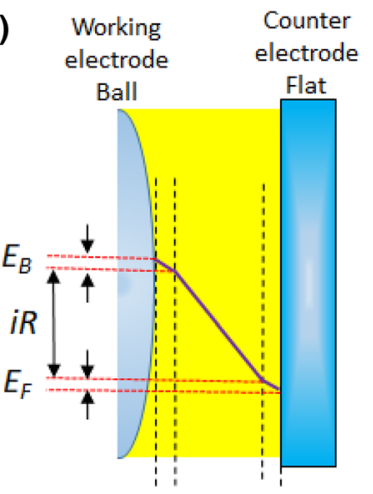

$E_{B}$ is driving force for reaction on ball

$$
U=E_{B}+i R+E_{F}
$$

Fig. 2 Two-electrode cell; a schematic arrangement; b electrical potential drop across contact. Adapted from [21] (a)

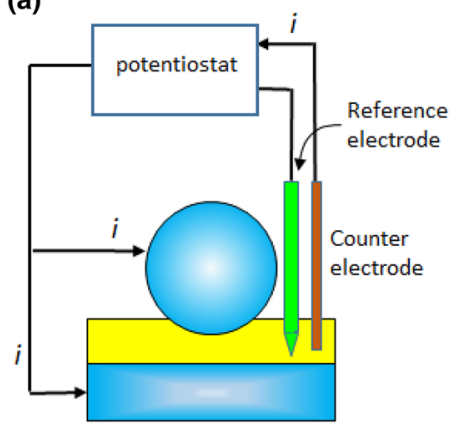

No current flow through reference electrode

$E_{W}$ is driving force for reaction on both ball and flat

Fig. 3 Three-electrode cell; a schematic arrangement; b potential drop across contact. Adapted from [21]

applied electrical and magnetic fields can be used to control friction actively [9].

The current review is concerned primarily with the effects of applied electrode potentials on the interaction of lubricants and additives with rubbing surfaces and consequent friction and sliding wear behaviour, together, in Sect. 6, with an outline of their use to assess lubricant degradation. Electric fields and their effects can impact tribological systems in many other ways, for example via arcing across contacts to cause surface damage, especially in bearings [10, 11], streaming potentials [12], electrorheological response [13], bubble formation and damage therefrom [14, 15], tribocharging [16] and triboemission [17]. They can also be used to measure both lubricant film thicknesses and the extent of asperity contact in mixed lubrication conditions $[18,19]$. Although important, these are not discussed in the current paper.

\section{Basic Electrochemical Concepts and Methods}

Before reviewing research carried out to study the impact of applied potential on lubricant behaviour, a few basic concepts and methods used in electrochemistry must be outlined. More detailed information on electrochemistry can be found in [20].

\subsection{Electrochemical Cells}

A diagram of a very simple electrolytic cell is shown in Fig. 1. Two electrodes are immersed in a liquid electrolyte. A potential difference is applied between the electrodes making one, the anode, positive, while the cathode is negative. If the electrolyte is only weakly ionically conducting, 
a supporting electrolyte (an ionic salt) can be dissolved in the electrolyte to enhance electrical conductivity. This minimises the ohmic potential drop within the electrolyte itself so that potential drop between anode and cathode occurs primarily at the electrode I electrolyte interfaces. During operation, if suitable reagents are available and the potential differences between the electrodes and the electrolyte are large enough, a reduction half-reaction involving gain of electrons occurs at the cathode, e.g.

$3 \mathrm{Fe}_{2} \mathrm{O}_{3}(\mathrm{~s})+2 \mathrm{H}^{+}(\mathrm{l})+2 \mathrm{e}^{-} \rightarrow 2 \mathrm{Fe}_{3} \mathrm{O}_{4}(\mathrm{~s})+\mathrm{H}_{2} \mathrm{O}(\mathrm{l})$

$2 \mathrm{H}^{+}(\mathrm{l})+2 \mathrm{e}^{-} \rightarrow \mathrm{H}_{2}(\mathrm{~g})$

$\mathrm{RSSR}(\mathrm{l})+2 \mathrm{e}^{-} \rightarrow 2 \mathrm{RS}^{-}(\mathrm{s})$

while oxidation, involving loss of electrons, occurs at the anode by reactions such as:

$\mathrm{Fe}(\mathrm{s}) \rightarrow \mathrm{Fe}^{2+}(\mathrm{s})+2 \mathrm{e}^{-}$

$2 \mathrm{H}_{2} \mathrm{O} \rightarrow \mathrm{O}_{2}(\mathrm{~g})+4 \mathrm{H}^{+}(\mathrm{l})+4 \mathrm{e}^{-}$

$\left[(\mathrm{RO})_{2} \mathrm{PS}_{2}\right]_{2} \mathrm{Zn}(\mathrm{l}) \rightarrow \mathrm{Zn}^{2+}(\mathrm{s})+\left[(\mathrm{RO})_{2} \mathrm{PS}_{2}\right]_{2}+2 \mathrm{e}^{-}$

It should be noted that even in the absence of an applied electrode potential (at open circuit), a metal electrode will possess a rest or equilibrium electrode potential relative to a standard (usually a standard hydrogen electrode (SHE), based on reaction [2] above) reflecting the ease with which it gains or loses electrons relative to the standard.

In practice there have been two main arrangements of experimental cell to study the influence of applied electrical potentials on rubbing, lubricated contacts, as shown schematically in Figs. 2 and 3, in which an electronically conducting sphere is rubbed against an electronically conducting flat, both immersed in lubricant (electrolyte).

The simplest case is shown in Fig. 2a, in which a DC voltage is applied across the lubricated contact. This was the system used by Edison and has been employed by some other researchers when studying the influence of potential on the behaviour of oil-based lubricants. As discussed later in this review it may also be the most practical arrangement for applying potentials to influence friction and wear in realistic, oil-lubricated systems.

The key advantage of this arrangement is simplicity but it has two main limitations. The first is that one of the rubbing components becomes the cathode and the other the anode. This means that different interactions with the lubricant are likely to take place within the same contact. This asymmetry is compounded if one surface is stationary and the other sliding, since in this case different overall response would be expected depending on the direction of the electric field resulting from the applied potential difference. A more fundamental limitation concerns the way that the potential drops between the two electrodes, as shown in Fig. 2b. Reactions at an electrode are determined by the difference in potential between the electronically conducting electrode surface and the ionically conducting electrolyte immediately adjacent to it. However, because current flows between the electrodes, the potential falls in an indeterminate way between them and the critical potential difference at the electrode surface is not well defined. The fact that lubricant films are very thin and thus might provide limited resistance even when using low electrical conductivity lubricants may mitigate this problem to some extent, although, as discussed later in this review, it may also result in intermittent metal-metal contact and thus shorting.

This second limitation can be addressed in triboelectrochemical research by using a three-electrode cell in which the two rubbing surfaces are coupled together as the working electrode and a separate counter electrode and, importantly,
Fig. 4 a Nature of electrical double layer with aqueous electrolytes; $\mathbf{b}$ Variation of potential across the double layer to reference electrode (a)

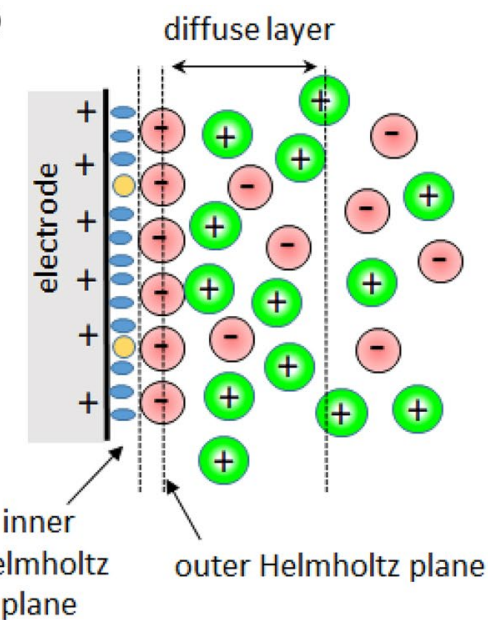

(b)

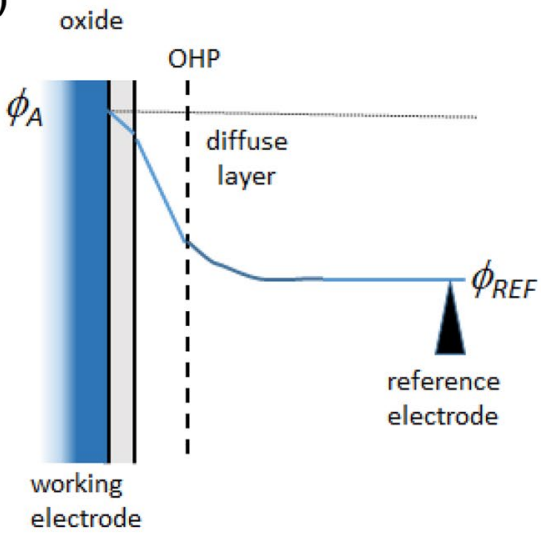


a third reference electrode are introduced, as shown in Fig. 3a. The resistance of the reference electrode part of the circuit is very large so that all the current flow is between the working and counter electrode, but the actual potential of the lubricant relative to the working electrode is controlled by the reference electrode, as shown in Fig. 3b. This arrangement is the mainstay for determination of the kinetics and mechanisms of electrochemical processes at individual working electrodes, enabling measurement of current and hence, according to Faraday's law, reaction rate as a function of applied potential. Another advantage in terms of tribology is that, as shown in Fig. 3, both of the rubbing surfaces are subjected to the same potential and so should interact similarly with the lubricant. Alternatively, this arrangement can be used to study the influence of applied potential on the tribological properties of a metal component as working electrode rubbing against an insulator, such as ceramic, glass or polymer. There are still considerable problems in three-electrode cells with very low conductivity fluids such as hydrocarbon oils, which will be discussed in Sect. 5 of this review.

\subsection{Electrical Double Layers}

To understand the impact of applied electrode potential on friction and wear, it is important to appreciate how this potential influences the nature of the electrode I electrolyte interface. Figure $4 \mathrm{a}$ shows a schematic model of an electrode at an oxidising potential immersed in aqueous electrolyte. Immediately adsorbed on the electrode surface is a layer of water dipoles, oriented in the electric field and also, depending on the solution composition, chemically adsorbed ions. This is the "inner Helmholtz plane". Beyond this is the "outer Helmholtz plane", the locus of approach of hydrated

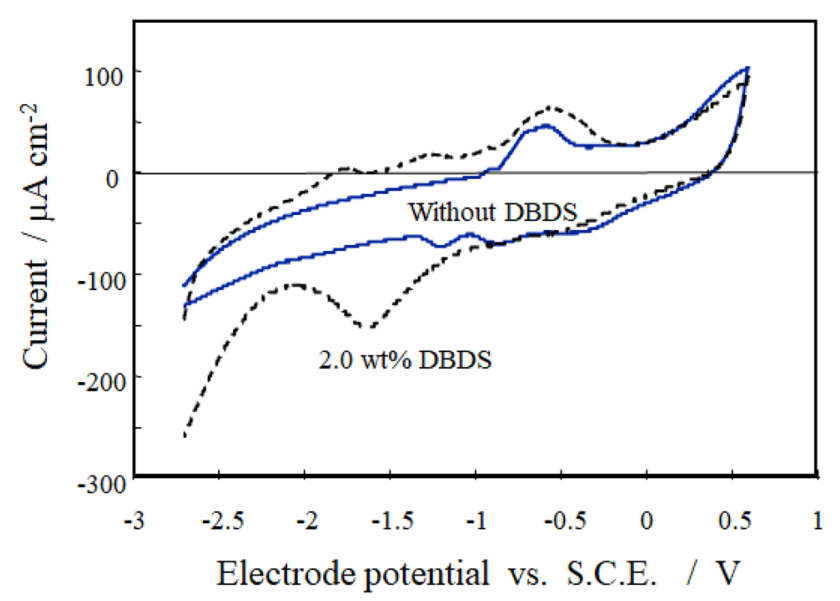

Fig. 5 Cyclic voltammograms of Pt I diethyl adipate $/ \mathrm{LiClO}_{4}$ with and without DBDS; potential scan rate $100 \mathrm{mV} / \mathrm{s}$ at $25{ }^{\circ} \mathrm{C}$. Reproduced from [33], with permission from Taylor \& Francis ions of opposite charge to that of the electrode surface and to which they are attracted to the surface by electrostatic forces. These layers create a charge imbalance in the electrolyte, so outside this is "diffuse layer" with a preponderance of ions of opposite charge, thermally dispersed into the solution to a distance known as the "Debye length" that is inversely dependent on the square root of the ionic strength. Beyond this layer the solution becomes balanced with equal density of cations and anions. The two Helmholtz planes and the diffuse layer make up the "electrical double layer".

Figure $4 \mathrm{~b}$ shows how the potential varies from the electrode out to the reference electrode in an aqueous threeelectrode electrochemical with a relative applied electrode potential, $E=\phi_{\mathrm{A}}-\phi_{\mathrm{REF}}$, which, depending on its value, may drive electron transfer across the electrode I electrolyte interface.

It should be noted from the above that as well as promoting redox reactions, the applied electrode potential may change the surface charge of metal [22] and oxide-covered metal [23] surfaces, so influencing the adsorption of ionic and polarisable species at the outer Helmholtz plane. As described later in this review, this adsorption itself can have a significant effect on friction.

The situation in non-aqueous, low electrical conductivity liquids such as hydrocarbon lubricants is broadly similar, though less fully quantified. The outer Helmholtz plane comprises adsorbed, charged ions from weak electrolytes present [24], most commonly additives or oxidation products. The diffuse double layer has thickness of order of the Debye length, $\lambda=\left(\varepsilon D / \sigma_{0}\right)^{0.5}$, where $\varepsilon$ is the electrical permittivity, $D$ the molecular diffusivity, and $\sigma_{0}$ the electrical conductivity $[24,25]$. The relative electrical permittivity of lubricants (the dielectric constant) is much lower than that of water but so is the electrical conductivity. The latter tends to overwhelm the former so that the diffuse layer is usually larger than for aqueous solutions. Because of their low electrical permittivity compared to water, the electrostatic

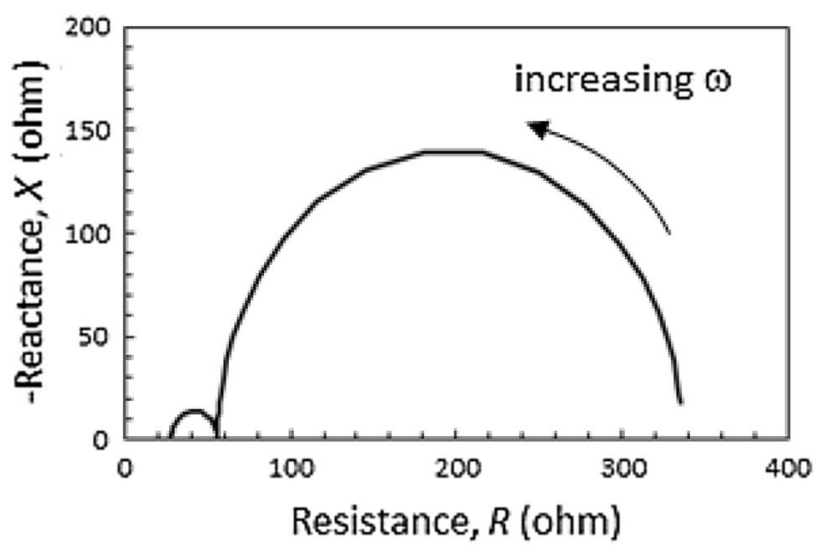

Fig. 6 Example Nyquist plot from an aqueous electrolytic cell 
forces between charged species are considerably higher, so that any dissolved species consisting of small ions tend to be predominantly in the form of ion pairs with very few free ions [26]. The main source of charged species in lubricants is therefore often large charged entities, such as carbon particles or detergent micelles [26, 27], and when these are present they can give diffuse layers of several hundred nanometers thickness [26].

\subsection{Electrochemical Measurements: DC Electrode Potentials}

Electrochemical reactions are studied most commonly by applying a relative electrode potential and monitoring the resulting current density. There are several protocols for doing this but two commonly used for determination of electrochemical kinetics are cyclic voltammetry and chronoamperometry. In cyclic voltammetry, the electrode potential of the working electrode is swept between potential limits at a fixed potential scan rate over one or more cycles, while monitoring the resulting current density. Positive and negative current densities correspond to oxidation and reduction reaction rates, respectively. Since it is a non-steady-state technique, cyclic voltammetry is not suited to explore the effect of electrode potential on friction and wear, but some studies have used it to determine the redox behaviour of lubricant additives [28-35]. Figure 5 compares cyclic voltammograms of the ester base oil, diethyl adipate, containing $\mathrm{LiClO}_{4}$ (as supporting electrolyte) with and without $2 \mathrm{wt} \%$ dibenzyldisulphide (DBDS), an extreme pressure additive [33]. DBDS is reduced at negative potentials to benzyl mercaptide ions by Reaction [3] in section 2.1 above. Figure 5 shows voltammograms of a Pt electrode, but with Fe electrodes this reduction is accompanied by a large decrease in wear rate, presumably due to a tribofilm formed by reaction between the mercaptide ions and the iron surfaces [33].

In chronoamperometry a fixed potential is applied to the working electrode and the time dependence of the resulting current density is monitored. When a single, known electrode reaction occurs, application of Faraday's Law provides a measure of rates of reaction, whether these are diffusion controlled and whether surface films develop to suppress them. This method has also been applied in tribology

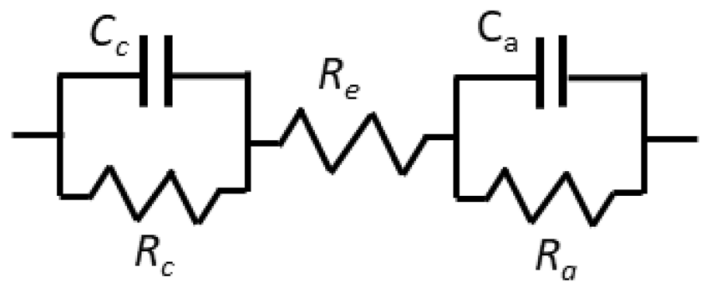

Fig. 7 Representative electrical circuit of an electrolytic cell research both to study lubricant additive response to applied potential in electrochemical cells and also across rubbing contacts, where rubbing may prevent accumulation of insulating tribofilms [34, 36-39].

\subsection{Electrode Impedance Spectroscopy: AC Potentials}

Figure 2 shows a DC potential difference applied across the contact. However, varying frequency AC can also be applied and the current response monitored to determine the impedance of the contact and how this depends on frequency. The variation of this impedance with AC frequency can then be analysed to determine the resistance and capacitance (or dielectric constant) of the contact or cell. In practice the impedance (or complex resistance), $Z$, has both real and imaginary components;

$Z=R+j X$

where $R$ is the resistance and $X$ is the reactance.

When a sinusoidal, low amplitude potential difference (typically $\leq 10 \mathrm{mV}$ ) is applied across the cell or contact, the resulting current will vary sinusoidally but generally will be phase-shifted. The ratio of the amplitude of the potential difference to the current is the resistance of the cell, $R$, while the phase shift, $\delta$, originates from capacitance and inductance components present;

$\delta=a \tan \left(\frac{R}{X}\right)$

A typical set of measurements from an aqueous electrolytic cell are shown in Fig. 6, in the form of a Nyquist plot in which the reactance is plotted against the resistance over a range of $\mathrm{AC}$ frequencies.

In order to interpret these measurements, the contact or cell must be represented by an electrical circuit containing the main components believed to be present [40]. This is illustrated in Fig. 7, where the cathode and anode are each represented by a resistor, $R_{\mathrm{c}}$ and $R_{\mathrm{a}}$ (Faradaic resistances), in parallel with a capacitor, $C_{\mathrm{c}}$ and $C_{\mathrm{a}}$ (the capacitance of the double layers), and these are in series with a resistor representing the resistance of the electrolyte, $R_{\mathrm{e}}$.

Since a capacitor has reactance $1 / j \omega C$, the impedance at each electrode is;

$\frac{1}{Z_{\mathrm{c}, \mathrm{a}}}=\frac{1}{R_{\mathrm{c}, \mathrm{a}}}+j \omega C_{\mathrm{c}, \mathrm{a}}$

where $\omega$ is the angular frequency (equal to $2 \pi f$ where $f$ is the AC frequency).

The overall impedance of the cell is then given by;

$Z=Z_{\mathrm{c}}+R_{\mathrm{e}}+Z_{\mathrm{a}}$ 
By best fitting Eq. 10 to the measured cell $R$ and $X$ data over the frequency range, the values of the components shown in Fig. 7 can be determined.

In many cases more complex analogue circuits are required to represent the various components in a contact or cell that contribute to the overall impedance, as illustrated in Sect. 6. Impedance spectroscopy is one of the main techniques to measure the very low electrical conductivity of hydrocarbon-based lubricants and has also, based on the double layer capacitance, been used to measure the presence and thickness of adsorbed films on electrode surfaces [33, 41]. A DC offset can be applied so that at low frequencies, the consequences of slow electrochemical processes including diffusion and redox reaction kinetics are evident. As will be described in Sect. 6, in recent years electrochemical impedance spectroscopy has also become widely used to monitor lubricant degradation and contamination [42].

\section{Brief History of Triboelectrochemistry}

\subsection{Research on Aqueous Systems}

In 1874 Edison showed that an applied potential difference across a contact could alter the kinetic friction of a sliding contact. He explored a wide range of materials and found that some experienced a decrease in friction while with others friction increased [43]. Edison's approach was highly practical and non-quantitative, but it was soon followed by a series of more systematic studies. Unlike Edison, who applied a potential difference directly across the rubbing contact, these all used a three-electrode arrangement or, until the 1950s a two-electrode system in which one or both of the rubbing surfaces was the working electrode while the counter electrode was external to the contact. Until the 1970s all research was based on aqueous solutions.

In 1879 Koch showed that when a platinum sphere was made into an anode its friction against a glass surface was increased [44], while four years later Waitz found the friction of palladium and platinum against glass decreased at negative potentials and increased when positive potentials were applied [45]. In 1889 Krouchkoll reported that the friction of a small platinum wire brush rubbing against a rotating glass plate in a dilute aqueous acid increased when the brush was made an anode and decreased when it was the cathode [42].

In the 1940s, Rehbinder found that an external potential difference strongly influenced the friction of a glass sphere against a metal surface immersed in an aqueous electrolyte [46]. He suggested that the interfacial tension of the metal/ electrolyte decreased the hardness of the metal leading to

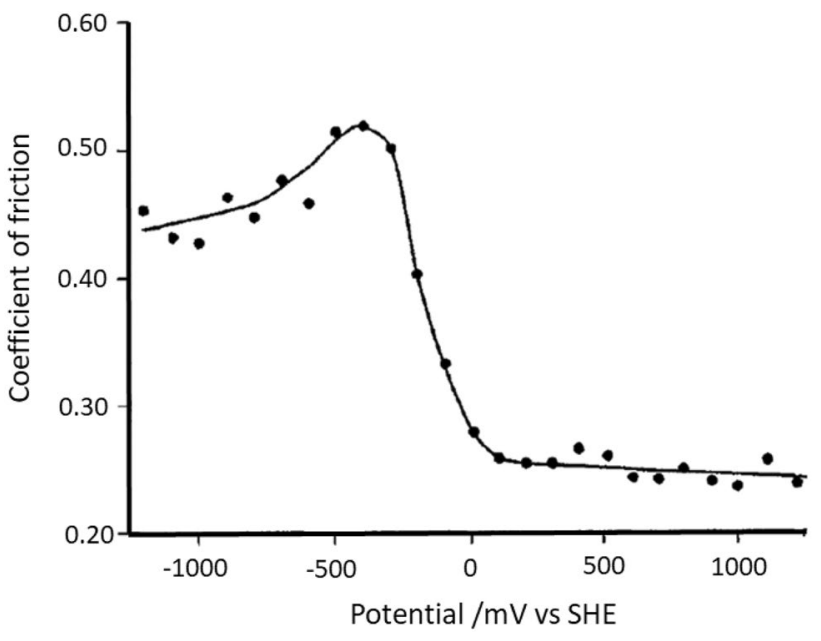

Fig. 8 Coefficient of friction vs. relative electrode potential for mild steel on iron in aqueous octanoic acid solution. $\mathrm{pH}$ adjusted to 9.2 with sodium hydroxide. Reproduced from [62], with permission from IOP Publishing, Ltd

decreased friction. However subsequent work by Bockris and Parry-Jones in 1953 [47] found that varying the electrode potential at a zinc electrode produced no measurable change in hardness. Instead these authors suggested the effect of applied potential on friction was due to its influence on surface adsorption of chemical species from the electrolyte.

In 1945 Clark carried out a series of experiments to measure friction of the contact between a rotating nonconducting drum and a metal wire as working electrode [48]. Friction increased at high negative electrode potential and he ascribed this to adsorption of metal cations.

The potentiostat was developed in 1942 [49], enabling control of individual electrode electrolyte interfaces against a reference electrode and as this became generally available it greatly facilitated electrochemical research. In 1950 Bowden and Young used a three-electrode system to measure the coefficient of static friction of platinum against platinum in sulphuric acid solution [50]. They showed that this gave low friction at both high and low electrode potentials with a maximum friction value accompanied by adhesive damage at an intermediate potential.

In 1961 Staicopolus employed a three-electrode system to measure effect of applied potential and electrolyte composition on the friction of copper and stainless steel against glass in a ball on conical cup rig [51]. He found that friction generally decreased at high and low electrode potentials, which he ascribed to adsorption of anions or cations, respectively, on surfaces to form a "lubricating" layer.

In 1969, Bockris and co-workers found that the coefficient of friction of platinum on platinum in perchloric acid solution reached a maximum at an intermediate potential that 
they identified as the point of zero charge [52]. They showed how the friction versus potential curve could be explained in terms of double layer repulsion [53, 54]. In 1975, Dubois and Lacaze proposed measurement of the change in friction with electrode potential as a method for studying metal solution interfaces in electrochemistry, a technique they termed polaromicrotribology [55].

In the 1980s attention focussed on the effect of applied potential on wear and the transition from adhesive wear at negative applied potentials to oxidative wear when positive potentials were applied to promote oxide formation [41, 56-61].

In 1992 Brandon et al. used a three-electrode system to study the effect of electrode potential on the friction of mild steel rubbing against iron in an alkaline solution of sodium octanoate [62]. They found a sharp decrease in friction at potentials greater than the potential of zero charge of iron $(-0.4 \mathrm{~V}$ vs standard hydrogen electrode) as shown in Fig. 8. Parallel radiotracer and impedance measurements showed that this corresponded to an increase in lubricant film thickness, suggested that octanoate anions were adsorbed on positively charged iron and steel surfaces.

In the following year Kelsall et al. studied the friction of metal and metal oxide sliding contacts while varying surface charge via both electrode potential and $\mathrm{pH}$ [63]. They found a maximum in friction at both intermediate applied potential and intermediate $\mathrm{pH}$ and showed that this was consistent with a model based on the loss of double layer repulsion causing the friction to increase under this condition.

Zhu et al. also studied the effect of applied potential on friction of a sodium octanoate solution, using IR spectroscopy to determine the nature of surface films formed on an iron electrode [64], and in 1996 combined an STM/AFM with a miniature electrochemical cell to map the formation of iron octanoate tribofilm in response to electrode potential at an iron flat $/ \mathrm{Si}_{3} \mathrm{~N}_{4} \mathrm{AFM}$ tip contact [29]. Lateral force microscopy was also employed in 1997 by Kautek et al. to study a $\mathrm{Si}_{3} \mathrm{~N}_{4}$ tip rubbing against silver under potential control; friction increased sharply at positive potentials in KBR solution but no such effect was seen with $\mathrm{KF}(\mathrm{aq})$ [65].

\subsection{Research on Non-aqueous Systems}

So far, this outline has been concerned only with aqueous solutions. The effect of applied potential on non-aqueous lubricated systems does not appear to have been investigated systematically until the 1970 s and then initial work with hydrocarbon-based lubricants was confined to studying the effect of applying a potential difference directly across a contact [36, 66-73]. This confirmed that even quite small applied DC voltages could significantly affect friction, wear, and scuffing [36, 67]. However, results were contradictory, with some studies reporting lower wear when the surface continuously in sliding contact was made the anode and others finding no difference or the opposite. Several studies found that applied potential increased or suppressed additive reactions at surfaces [68, 70,71]. More recently Gangopadhyay et al. used a similar approach by measuring the effect of applying a potential difference across a sliding lubricated contact on the friction and wear of formulated engine oils [74]. There was considerable impact on wear, which was reduced for the cathodic surface, but little effect on friction.

In the late 1980s Tung et al. carried out a series of experiments to study the influence of applied electric field on additive reactions on surfaces and the impact of consequent tribofilms on friction and wear [28, 75-79]. Using two electrodes with a $15-\mu \mathrm{m}$ gap to minimise resistance, and impedance spectroscopy to estimate film properties, they showed that large potential differences could cause zinc dialkyldithiophosphate (ZDDP) and some other additives dissolved in mineral oil to form films on unrubbed surfaces.

As discussed later in this review, to allow fundamental research using a three-electrode system, the practical problem of the very low conductivity of organic lubricants had to be addressed. For this, two advances in electrochemistry were needed; the use of supporting electrolytes soluble in organic solvents and the development of microelectrodes [80], and by the mid-1990s, these enabled three-electrode triboelectrochemical studies to be carried out in organic solvents. Initially the behaviour of ZDDP as an antioxidant was addressed [30, 32, 81-83]. It was found that both the oxidation of ZDDP and its formation of surface films were promoted by positive electrode potentials.

In $2000 \mathrm{Zhu}$ et al. reported results of a systematic study of the effects of electrode potentials in non-aqueous solvents on friction and wear of iron [33]. They explored various

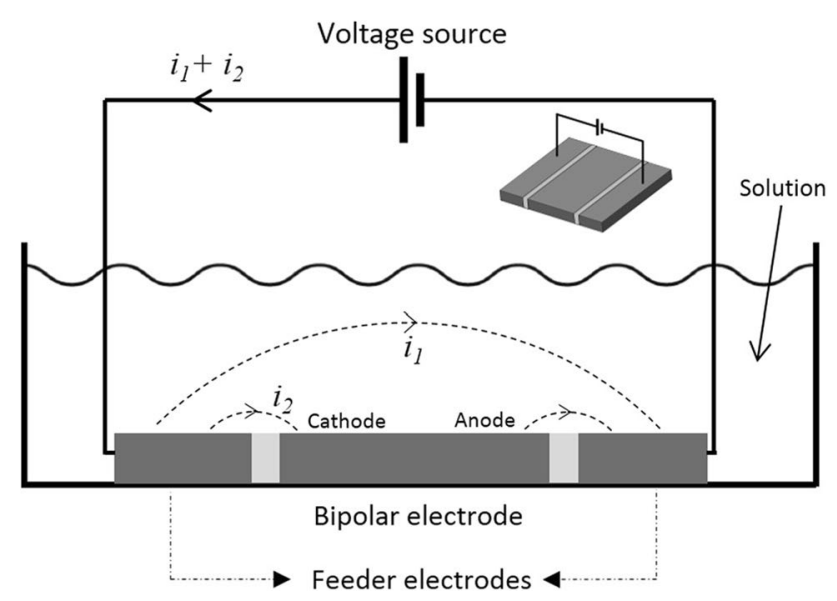

Fig. 9 Experimental setup for creating friction distribution showing the current paths on the bipolar electrode when current is applied in the solution by a pair of stainless steel feeder electrodes. Reproduced from [95], with permission from Springer Nature 
supporting electrolytes in solvents ranging from propylene carbonate to diethyl adipate and measured the effect of potential on friction and wear of lubricant additives including fatty acids and dibenzyldisulphide. This approach was extended by $\mathrm{Xu}$ et al., who developed supporting electrolytes capable of being dissolved in esters and even, to a limited extent, in hexadecane, thereby enabling the behaviour of ZDDP to be studied with a Pt electrode under electrode potential control in realistic lubricant base oils for the first time [84].

\subsection{Recent Research on Triboelectrochemistry}

The last decade has seen continued research on the impact of applied electrical potentials on lubricant behaviour. Ismail et al. studied the influence of applied electrode potential on the friction and wear behaviour of a sliding steel/steel contact lubricated by sodium octanoate solution [39] and found results very similar to earlier work by Brandon [62, 85], with low friction and wear when the steel was anodic. Meng and co-workers carried out an extensive series of studies on the influence of electrode potential of the tribological behaviour of metal/ceramic contacts using aqueous lubricants containing sodium dodecyl sulphate additive [34, 86-88]. They found that the additive was effective in decreasing friction at oxidising electrode potentials. Very recently Cao and Meng studied the response of ZDDP in a polycarbonate/ ester blend to applied electrode potential [89]. In 2011, Xie et al. studied the effect of large applied potential differences across a steel ball on coated glass disc contact lubricated by various organic liquids including a hydrocarbon and various alcohols [90]. They found an increase in film thickness at low speeds compared to elastohydrodynamic theory that they interpreted as an increase in viscosity due to the applied electric field.

There has been continued interest in using an AFM with an electrochemical stage to observe the influence of applied potential on friction at an atomic scale [91-94]. Nielinger and Baltruschat showed that the friction of a silver surface could be increased reversibly by depositing and dissolving copper on it from a sulphate solution using suitable electrode potentials [81]. The impact of anion type on friction of a gold surface has also been studied using sulphuric and perchloric acid solutions [92, 94].

Another recent advance has been the use by Zhang et al. of bipolar electrochemistry to study the influence of electrode potential on adsorption and friction [95]. In this, a single, rod or bar-shaped, ionically conducting electrode is immersed in electrolyte and a pair of driving or feeder electrodes located close, but not connected, to either end of this. These driving electrodes create a potential gradient within the electrolyte and this results in a potential difference between the electrolyte and the bipolar electrode that varies
Table 1 Proposed mechanisms by which applied electrode potentials influence friction and wear

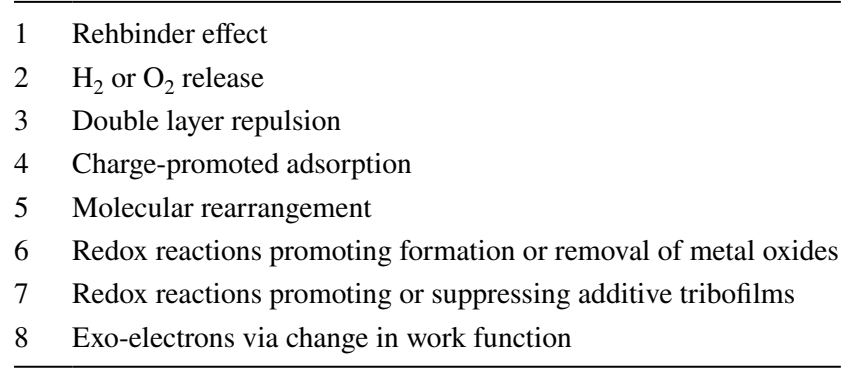

from one end of this electrode to the other [96]. Figure 9 shows the setup used by Zhang et al., who applied ellipsometry and friction measurement to show how adsorption and consequent boundary friction varied from the cathodic to the anodic end of the electrode [95].

An interesting development in recent years has been the use of ionic liquids both as base fluids and additives. These offer ionic conductivities that in some cases are high enough for potential control and, depending on the composition of their component ions, stabilities over a wide range of electrode potentials. Dold et al. showed that the friction of steel against steel lubricated by a pure ionic liquid in a three-electrode setup was influenced by applied potential [97]. Since some ionic liquids are soluble in base oils they may also act as supporting electrolytes in lubricants. Yang, Meng, and Tian have studied the effect of electrode potentials on Pt with solutions of imidazoline-based ionic liquid in propylene carbonate using cyclic voltammetry [98, 99]. They found that the solutions gave low friction at negative potentials and high friction at positive potentials that they ascribed to the adsorption of the cation and anion species, respectively. Recently, ionic liquids have also been studied quite extensively in the AFM/LFM to explore the effect of electrode potentials on the friction of gold and graphite surfaces [100-105]. The main focus has been on how applied potential controls cation and anion adsorption and thus friction, with the consequent possibility of active friction control. Most studies have used neat ionic liquids but recently it was shown that the friction of a silicon tip rubbing against gold under potential control in solutions of ionic liquids in alkanes was similarly responsive to changes in electrical potential [105].

Another area of growing interest has been the application of molecular modelling to model and perhaps predict the effects of applied potential on lubrication. Ma and Shrotiya studied the response of adsorbed surfactant monolayers to an applied electric field [106]. No effect was predicted for close-packed monolayers but with partial monolayers, positive electrode potentials promoted structural changes that produced lower friction. In 2015 Manzato et al. used molecular dynamics to explore the effect 
of electric fields on lubrication by nematic liquid crystals [107]. They predicted a decrease in friction when the field was applied along the sliding direction. In the same year Fajardo et al. employed coarse grain non-equilibrium molecular dynamic to model confined liquid crystal films film between surfaces while applying partial charges to the bounding substrate surfaces to simulate an applied electric potential [108]. They reported that the applied field produced significant structural changes with resulting large variations in friction.

\section{Proposed Mechanisms of Friction and Wear Response}

Although the main focus of this review is on the influence of applied potentials on non-aqueous organic liquids, it is useful first to examine the insights provided by research on aqueous systems, since electrochemical effects in these are more easily interpreted and generally more quantitative. In particular, studies with aqueous solutions have enabled identification of most of the main mechanisms by which applied electric potentials may influence friction and wear.

Edison appears to have spent little effort to explore possible mechanisms of how potential differences influenced friction. Initially he suggested that evolved hydrogen might reduce metal oxides to reduce friction [1] but later observed similar behaviour with oxide-free platinum

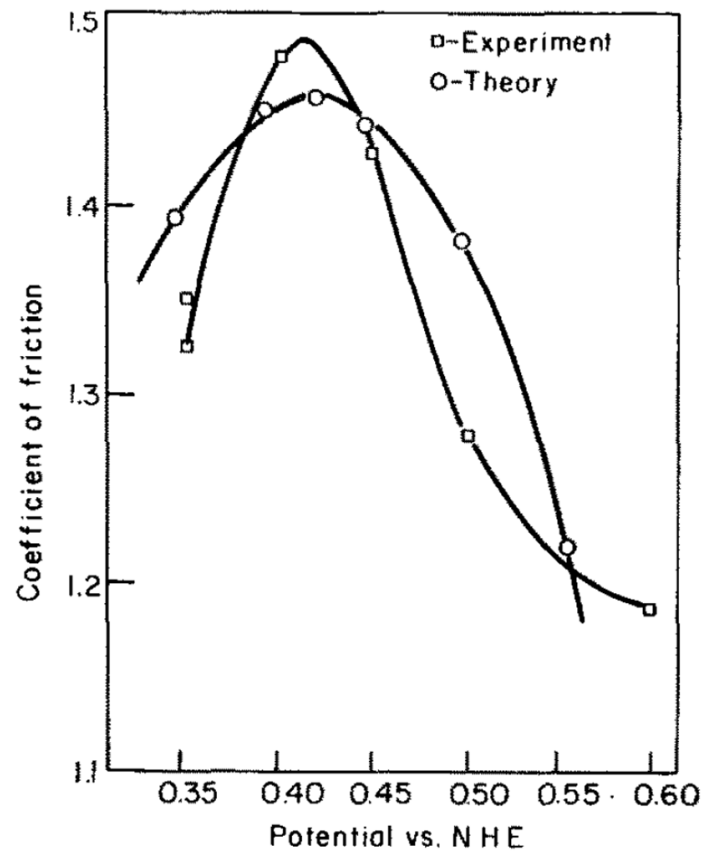

Fig. 10 Coefficient of friction versus potential for Pt on $\mathrm{Pt}$ in $\mathrm{HClO}$. Reproduced from [53], with permission from Elsevier
[2]. However since then several different mechanisms have been proposed to explain the effects of applied potentials on friction and wear in aqueous systems. These are listed in Table 1.

\subsection{Rehbinder Effect}

In the 1930s and 1940s Rehbinder proposed that the adsorption of surfactants on solids could alter the latters' mechanical properties, including their hardness. He ascribed this to penetration of the surfactant into ultramicroscopic cracks produced during deformation of the solid [109]. In 1944 he used Herbert pendulum type equipment to measure the effect of applied potential on oscillation of a glass ball on an $\mathrm{FeS}_{2}$ flat and found that frictional damping was maximal at intermediate potentials [46]. Rehbinder interpreted his results in terms of a decrease in hardness at low and high applied potential differences. This hypothesis was controversial and Andrade and Randall suggested that Rehbinder's observed effect resulted from variations in friction from disintegration of an oxide film [110] while Bockris and Parry-Jones in 1953 [47] found that varying the electrode potential produced no measurable change in hardness for zinc, while still giving maximal friction at intermediate potential.

The concept that surfactant adsorption can affect subsurface mechanical properties, now generally known as the Rehbinder effect, has often been considered with some scepticism, without ever being wholly disproved. In 1951 Kramer reviewed the influence of the environment on the mechanical properties of metals and suggested various possible mechanisms that might be influential [111]. More recently Westwood and Lockwood have discussed possible mechanisms of these "chemomechanical effects" [112].

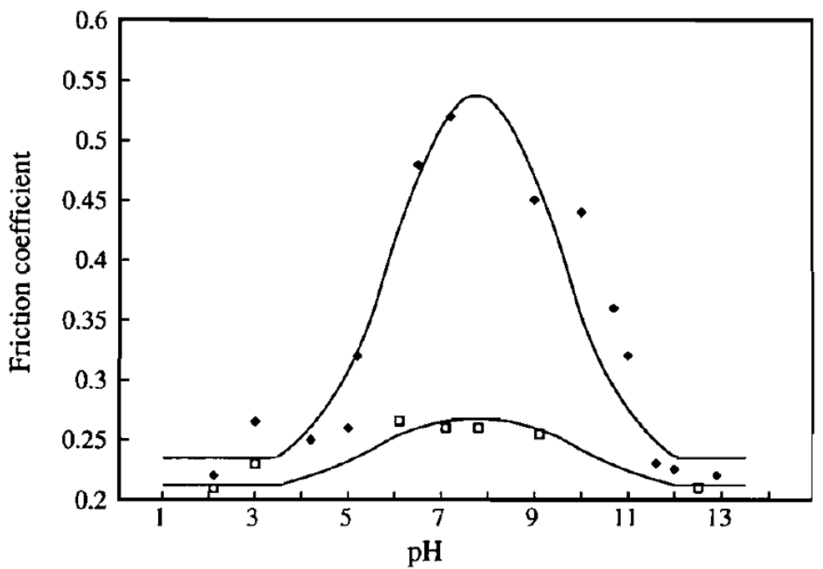

Fig. 11 Comparison of theoretical (lines) and measured friction coefficients (points) for $\mathrm{Al}_{2} \mathrm{O}_{3}$ rubbing on $\mathrm{Fe}_{2} \mathrm{O}_{3}$ at different $\mathrm{pH}$ values (solid diamond 2.8 MPa, hollow square $=7.8 \mathrm{MPa}$ ). Reproduced from [64], with permission from Taylor \& Francis 


\section{2 $\mathrm{H}_{2}$ or $\mathrm{O}_{2}$ Release}

Bowden and Young studied the friction of a platinum wire on a platinum cylinder subject to electrical potential in dilute sulphuric acid [50]. They found high friction at intermediate potentials and lower friction at negative and high potentials and, based on previous work on the influence of gases on the friction of clean metals [113], they proposed that the reduced friction regions corresponded to the formation of monolayers of hydrogen and oxygen, respectively. However there appears to be no direct evidence of such monolayers and the authors also proposed a parallel mechanism based on electrical double layer repulsion as outlined below.

\subsection{Double Layer Repulsion}

Both Bowden and Young, and Rehbinder found that variation of applied potential often produced a parabolically shaped response curve, with a high value of friction at intermediate potentials (ca $0.4 \mathrm{~V}$ relative to SHE) but much lower values at both low and high potentials. In the 1950s and 1960s Bockris and co-workers proposed that this shape resulted from the occurrence of double layer repulsion between the rubbing surfaces at low and high applied potentials that reduced the effective load in the contact, thereby producing decreased in friction coefficient [52-54]. Hence, the maximum value of friction at intermediate potential occurred at the potential of zero charge at which there was no such repulsion effect. They developed a series of

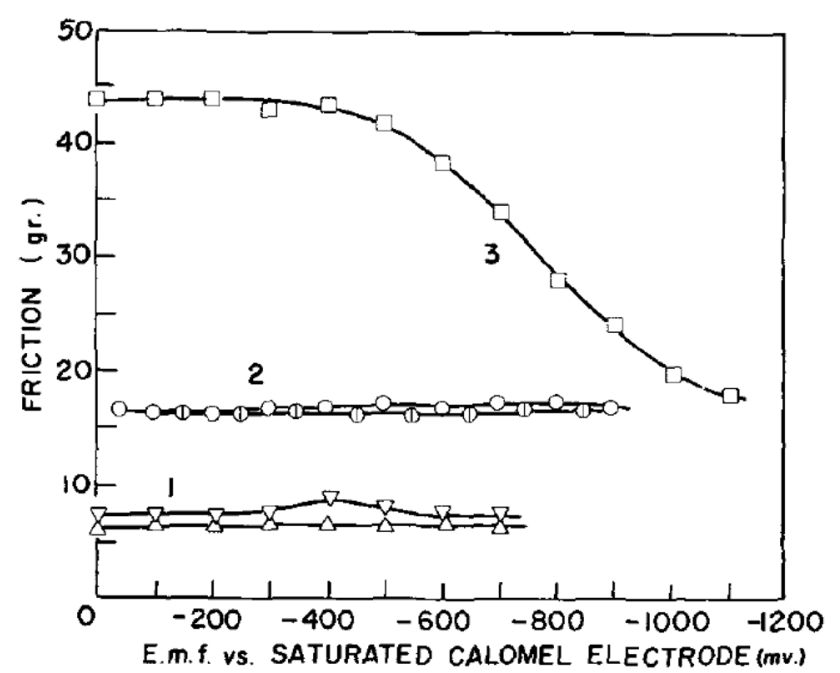

Fig. 12 Effect of applied potential on friction: copper against glass, open triangle $1 \mathrm{M} \mathrm{Na}_{2} \mathrm{SO}_{4}+10^{-2} \mathrm{M}$ p-aminophenol; open inverted triangle $1 \mathrm{M} \mathrm{Na}_{2} \mathrm{SO}_{4}+10^{-2} \mathrm{M}$ o-aminophenol; open circle $1 \mathrm{M}$ $\mathrm{Na}_{2} \mathrm{SO}_{4}+10^{-1} \mathrm{M}$ glycine (increasing polarisation); open circle with a line through centre $1 \mathrm{M} \mathrm{Na}_{2} \mathrm{SO}_{4}+10^{-1} \mathrm{M}$ glycine (decreasing polarisation); open square $1 \mathrm{M} \mathrm{Na}_{2} \mathrm{SO}_{4}+0.1 \mathrm{M}$ o-aminophenol (Na salt). Reproduced from [51], with permission from IOP Publishing, Ltd. models to predict the effect and obtained quite good agreement between their model and experiments for platinum/ platinum sliding contacts, as shown in Fig. 10. Measurement of friction was even proposed as a means of determining the point of zero charge [54].

Although quite convincing, it was difficult to separate this proposed mechanisms from others that might give similar shaped response curves. However, in the early 1990s it received strong support from Kelsall et al., who used two different ways to create electrical double layers, by varying $\mathrm{pH}$ for rubbing ceramic contacts and varying applied electrode potentials for rubbing metal contacts [63]. Using a high frequency reciprocating rig (HFRR) with potential control they showed that both approaches gave similar parabolic-shaped friction responses, with a maximum at the point of zero charge in both cases and low friction at both low $\mathrm{pH} /$ negative potential and at high $\mathrm{pH} /$ positive potential. They developed a model of rough surface friction reduction based a combination of attractive short range van der Waal forces and repulsive longer range double layer forces. This predicted a net repulsive pressure that decreased the effective load on asperities and the consequent impact on friction agreed well with experimental data, as shown in Fig. 11 for the friction of $\mathrm{Al}_{2} \mathrm{O}_{3}$ rubbing against $\mathrm{Fe}_{2} \mathrm{O}_{3}$ in $\mathrm{Na}_{2} \mathrm{SO}_{4}$ solution at various $\mathrm{pH}$ values [64]. Results at two loads are shown, indicating that, as expected, the effect was much smaller at higher than at lower loads. The authors calculated that the maximum electrostatic pressure was $2 \mathrm{MPa}$, suggesting that this double layer repulsion effect is significant only in low pressure contacts, in the MPa range. It is noteworthy that most early experiments tended to use very lightly loaded rubbing contacts based on glassware apparatus, in which these electrostatic effects would be most evident.

\subsection{Charge-Promoted Adsorption}

The above mechanism is based on the concept that opposing double layers decrease the effective contact pressure. However, the adsorbed layer of hydrated ions at the outer Helmholtz plane may also play a role in decreasing friction by providing a plane of easy (or difficult) slip. In 1961 this was proposed by Staicopolus, who measured the friction of metal rubbing against glass in various salt solutions under electrode potential control [51]. He found that some ions, including most cations and sulphate anions, did not adsorb or affect friction, while others, including cerium cations, and chloride anions adsorbed and desorbed reversibly, and, when adsorbed acted as a lubricating layer. Interestingly, Staicopolus also tested two zwitter-ion compounds, glycine and aminophenol, that can carry both positive and negative charge and found that these reduced friction at all potentials. However, if the ability of aminophenol to form a protonated cation was supressed by converting it to a sodium salt, no 
decrease in friction was observed at low potentials (Fig. 12). This result provided strong evidence that layers of adsorbed ions were controlling friction.

Brandon et al. also proposed that applied electrode potential could promote the adsorption of surfactant to form friction-reducing boundary films [62]. For a steel/iron contact immersed in aqueous sodium octanoate solution they found that friction decreased at applied potentials more positive than the potential of zero charge which, they suggested, was due to adsorption of negatively charged octanoate ions on the positively charged surfaces. More recently $\mathrm{He}$ et al. have measured a similar decrease in friction at positive potentials with aqueous solutions of sodium dodecyl sulphate lubricating a stainless steel $/ \mathrm{ZrO}_{2}$ sliding contact [88]. Based on parallel quartz crystal microbalance (QCM) and AFM work they demonstrated that positive applied potential promoted adsorption of dodecylsulphate anions and that the resulting monolayer and/or micellar film decreased boundary friction. This has been confirmed by Zhang et al. who combined a bipolar electrode with ellipsometry to show how a gradient of adsorption of sodium dodecylsulphate and consequent friction could be established across a surface via an electric field gradient in the electrolyte [95].

As well as adsorption of surfactants, the adsorption of charged nanoparticles on tribological surfaces can also be controlled using applied potential. Liu et al. studied the friction behaviour of nanoparticles dispersed in diethyl succinate in a $\mathrm{ZrO}_{2} / \mathrm{Cu}$ contact and found that applied negative potential could promote adsorption and reduce friction of positively charged $\mathrm{CuS}$ nanoparticles [114], while positive potential could promote adsorption and thereby reduce friction of negatively charged $\mathrm{MoS}_{2}$ nanoparticles [115].

In recent years lateral force microscopy with an electrochemical system has been used quite extensively to study the effects of anion adsorption on the friction of silver and gold. At intermediate potentials, below that at which gold oxidises, it was found that anions that specifically adsorb in the inner Helmholtz layer on noble metals $\left(\mathrm{Cl}^{-}, \mathrm{SO}_{4}{ }^{2-}\right.$, $\mathrm{OH})$ influence friction, while those that only adsorb in the outer Helmholtz layer, without chemical bonding to the surface $\left(\mathrm{F}^{-}, \mathrm{ClO}^{4-}\right)$, do not $[65,93]$. The main difficulty in such studies appears to be to avoid redox processes such as metal oxidation/reduction that can overlay or compete with changes in friction solely due to adsorbed ionic species.

\subsection{Molecular Rearrangement}

Another way that an applied potential may influence friction is by inducing a conformational change on molecules between a pair of rubbing surfaces. In 1994 Kimura et al. reported the effect of applied DC potential differences across a sliding pin on steel ball contact lubricated by a thermotropic liquid crystal. Their results demonstrated that as the magnitude of the applied difference was increased, greater decrease in friction resulted [116]. Similar decreases in friction were measured with low frequency $\mathrm{AC}(<1 \mathrm{~Hz})$. They suggested that the electric field was influencing an order-disorder transition of the liquid crystal. Recently Drummond has reported the impact of applied potential differences on adsorbed polymer layers on crossed cylinder surfaces immersed an aqueous electrolyte in a surface forces apparatus [117]. The two surfaces were immersed in an aqueous electrolyte. DC potential differences had negligible effect, but extremely low friction resulted when AC potential differences were applied up to $600 \mathrm{~Hz}$, above which the effect was lost. Drummond proposed that rapid movement of counter-ions in solution in response to applied AC potential differences caused stretching and bending of the polymer chains that had the effect of eliminating the interpenetration of opposing layers. The effect was lost when the polymer could not response fast enough to its changing environment.

It has also recently been shown that applied potential can have a large effect on the friction measured in AFM contacts immersed in $\mathrm{NaCl}$ solution, with high friction at negative potentials relative to a silver quasi reference electrode, and low friction at positive potentials [118, 119]. This was ascribed to the formation of a highly viscous or solid-like, nanometer-thick, ordered multilayer of water molecules on hydrophilic surfaces hydrogen bonded to the surface at negative potential.

The above mechanisms can be considered as primarily physical in nature since they do not involved redox reactions or chemical bond-breaking stimulated by applied potential differences. The following three possible mechanisms involve oxidation or reduction reactions driven by the electrode potentials at electrode/solution interfaces. For clarity,

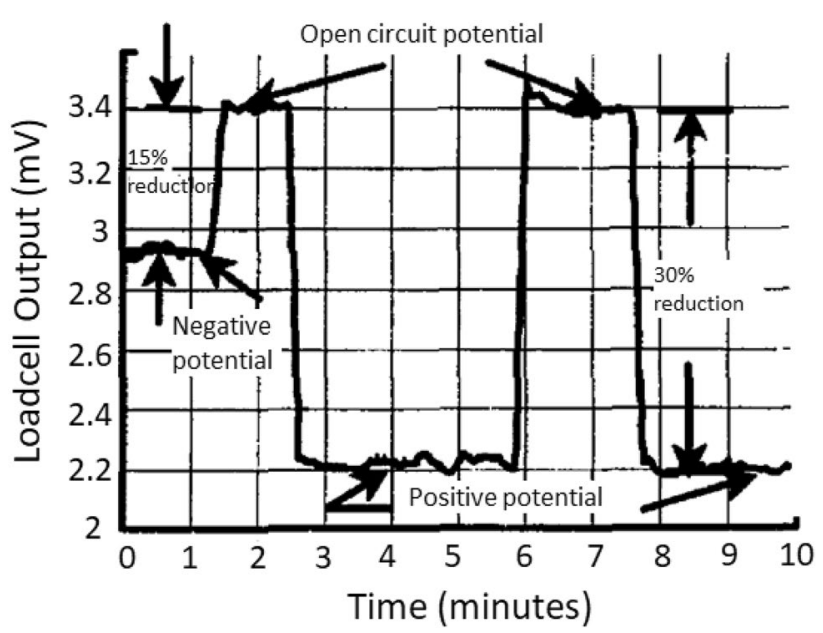

Fig. 13 Load cell output, proportional to the friction force, during an industrial wire drawing test. Reproduced from [121], with permission from Elsevier 
redox reactions are divided into two types; (i) those in which applied electrode potentials drive oxidation/reduction of the electrode itself, in particular oxide formation at positive potentials and oxide reduction at negative potentials and (ii) when the applied electrode potentials oxidise or reduce components in the solution to form or remove tribofilms.

\subsection{Redox Reactions Promoting or Removing Metal Oxides}

Metal electrodes in aqueous solutions are oxidised with increasing electrode potentials and reduced at decreasing electrode potentials, possibly in parallel with water oxidation or reduction depending on the particular metal's reactivity. This explains why most early research on the impact of electrical potential on friction employed platinum electrodes which did not oxidise over the potential range of interest.

Throughout the 1980s several studies were made of the influence of applied potential on the oxidative wear of metals, generally with the aim of reducing this type of wear in both sliding and fretting conditions, though sometimes, for example in electrolytic grinding, of increasing the rate of material removal. The work, which has been summarised by Pearson, demonstrated that as the applied potential is increased from a highly negative value, initially an oxide film forms, which may be a passivating layer but may be removed mechanically, accelerating wear rate [61]. Pearson concluded that applied electrode potentials could provide cathodic protection, eliminating corrosion and some fretting wear, but he also noted the undesirability of applying such negative potentials as to cause hydrogen evolution which might promote embrittlement.

In 1994 Zhu et al. measured the effect of electrode potential on the friction and wear of iron sliding on iron and used IR spectroscopy to analyse iron surfaces under potential control [64]. As potentials were increased they measured both a decrease in friction and a large increase in wear, corresponded to the conversion of $\mathrm{Fe}_{3} \mathrm{O}_{4}$ to $\mathrm{FeOOH}$. However, at very high potential, wear decreased due to the formation of a compact and hard $\mathrm{FeOOH}$ passivating layer.

Even noble metals can oxidise if the electrode potential is sufficiently high and this can produce a large change in friction. With silver on silver, Kautek et al. found a very large decrease in friction when the electrode potential was high enough to form silver oxide [65], but in studies using gold, researchers found that friction increased when the oxide was formed [94].

If surfactants are present, oxidation or reduction of metal electrode surfaces can change the interaction of those surfactants with such surfaces. Zhu et al. studied the influence of applied potential on the friction of a reciprocating iron/ iron contact lubricated with aqueous octanoic acid solution [64] and used IR spectroscopy to characterise the surface film formed. At positive electrode potentials, iron oxidised to form a surface film of iron(II) carboxylate, with a consequent decrease in friction.

In $1997 \mathrm{Su}$ studied whether applied potential could be used to improve the process of copper wire drawing lubricated by an $\mathrm{O} / \mathrm{W}$ emulsion containing fatty acids to provide boundary lubrication $[120,121]$. Su showed that the fatty acids could form a friction-reducing film only if the copper was coated with a thick copper oxide film, and that an applied positive electrode potential enabled such an oxide film to form rapidly enough to be effective at wire-drawing speeds. Figure 13 shows how friction varied with applied potential in an industrial wire-drawing machine.

\subsection{Redox Reactions Promoting or Suppressing Additive Tribofilms}

Applied potentials also may influence tribofilm formation and thus friction and wear by directly oxidising/reducing additives present in the electrolyte to promote or inhibit tribofilm formation. However, except for the suggestion that hydrogen and oxygen generated from water at very high and low potential may reduce friction, this does not appear to have been explored in aqueous lubrication, although, as described later in this review, there has been some research in non-aqueous systems, especially with respect to ZDDP.

\subsection{Exo-electrons}

When dry surfaces are rubbed together in dry and boundary lubrication conditions, several studies have shown that electrons may be emitted [122, 123]. If lubricant is present it has been proposed that these electrons may initiate radical reactions with the base oil or additives to promote tribofilm formation $[105,106]$. For metals, the energy required to emit electrons is the work function. Shor [67, 68] and Morizur and Briant [71] have suggested that the application of a positive electrode potential will decrease this work function by providing a greater availability of electrons at the surface and this will, in turn, promote additive reactions. Essentially this represents a coupling between mechanical forces and applied potential to stimulate surface oxidation reactions. It should be noted that there is little if any direct evidence for this mechanism to date so it remains conjectural.

\subsection{Summary of Mechanisms of Electrode Potential Effects on Friction and Wear}

From the above it is evident that there are several possible mechanisms by which applied potentials can influence friction and wear. Some, the Rehbinder effect, $\mathrm{H}_{2} / \mathrm{O}_{2}$ evolution and exo-electron emission remain unproven in this 
context and will not be considered further in this review. Double layer repulsion to reduce effective load is unlikely to be relevant to high pressure, oil-based lubricated contacts. However the remaining mechanisms, charge-promoted adsorption, electrochemically driven oxide or additive film formation and field-induced molecular rearrangement may all play a significant role in controlling friction and wear and are likely to be equally applicable to controlling friction and wear in non-aqueous systems as they are in aqueous systems.

\section{Non-aqueous Triboelectrochemistry}

As described in Sect. 3, research on the influence of applied potential on oil-based lubrication falls into two halves. In the 1970s to 1980s studies were based on simple two-electrode systems in which electric potential differences were applied directly across lubricated contacts. While little fundamental understanding emerged from this work, it did show that applied potentials could influence friction, wear and tribofilm formation. Morizur and Briant [71] and Wang et al. [28] showed that applied potential differences could promote ZDDP film formation, while Yamomoto and Hirano showed that tricresylphosphate formed a tribofilm preferentially on oxidised steel surface [36].

From the 1990s most researchers have used a three-electrode arrangement, in which both contacting surfaces were working electrodes (or just one if the other was non-conducting) and an electrical potential was applied against reference electrodes outside the contact. Such three-electrode methodologies will be described below, but first the advances that make it possible in organic lubricants will be outlined.

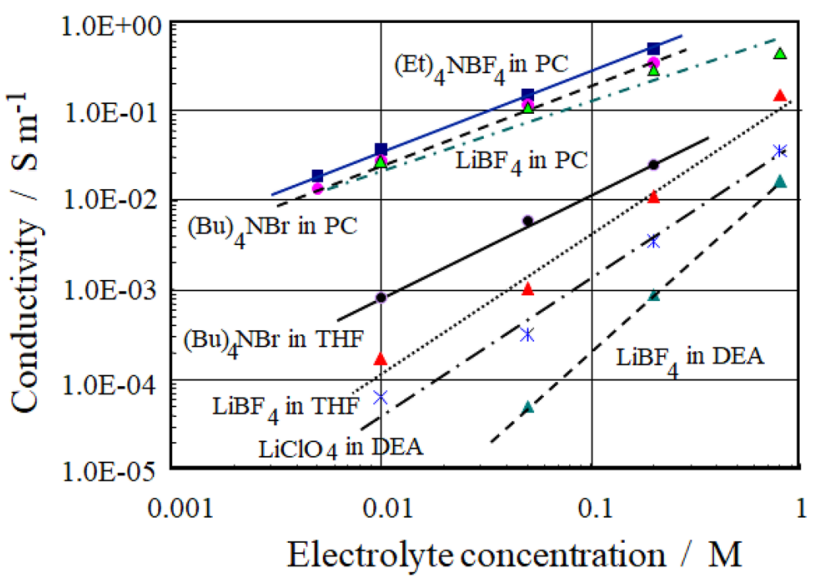

Fig. 14 Effect of supporting electrolyte concentration of electrical conductivities of non-aqueous solvents at $25{ }^{\circ} \mathrm{C}$. DEA is the ester diethyl adipate. Reproduced from [33], with permission from Taylor $\&$ Francis

\subsection{Electrical Conductivity Problem}

Aqueous solutions containing a dissolved salt as a supporting electrolyte have high ionic conductivities, e.g. ca. $8.5 \mathrm{~S}$ $\mathrm{m}^{-1}$ for $1 \mathrm{M} \mathrm{Na}_{2} \mathrm{SO}_{4}$, so that, as shown in Fig. $3 \mathrm{~b}$ most of the electrical potential drop occurs between the working electrode and the OHP, with little between the double layer and the reference electrode. The potential drop over path length $\mathrm{d}$ is $\Delta \varphi=i . d / \sigma$ where $i$ is the current and $\sigma$ is the electrical conductivity. Consequently, for aqueous solutions with large $\sigma$, the electrode potential that drives reactions at the electrode is well-controlled and well-defined. By contrast, most lubricant base oils are organic liquids with low dielectric constant and very low electrical conductivity, as such they are often termed dielectric liquids. A highly refined mineral base oil has electrical conductivity ca $10^{-14} \mathrm{~S} \mathrm{~m}^{-1}$ at $100^{\circ} \mathrm{C}$ [124] while formulated oils tend to lie in the range $10^{-10}$ to $10^{-8} \mathrm{~S} \mathrm{~m}^{-1}$, with the precise value depending on the polarity of the base oil, the presence and concentration of polar additives and contaminants, dissolved water and temperature [124-126]. Electrical conductivity increases very rapidly with temperature, primarily in response to decreasing viscosity and consequent increased mobility of charge-carrying species present, and there is a well-known inverse correlation between viscosity and electrical conductivity known as Walden's rule. Unless mitigated somehow, this low electrical conductivity means that the potential variation between electrodes occurs mainly in the bulk of the fluid so that there is negligible drop at the working electrode surface itself.

Bond and Mann [80] have described the two main approaches to solve this problem in electrochemical systems; (i) the use of secondary electrolytes soluble in organic solvents and (ii) micro/nanoelectrodes.

\subsection{Secondary Electrolytes}

Water itself has low electrical conductivity but this is greatly increased by dissolving salts or ion-producing compounds such as acids. Supporting electrolytes perform a similar role in non-aqueous solvents. Unfortunately few ionic compounds are soluble in organic liquids and even fewer in highly non-polar liquids such as esters and hydrocarbons. For this reason, most conventional non-aqueous electrochemical research has used polar organic solvents, most commonly acetonitrile (AN), propylene carbonate (PC), dimethylformamide (DMF) and tetrahydrofuran (THF). These solvents have also been employed in studies of lubricant additive behaviour under electrode potential control as outlined below. Supporting electrolytes must be soluble in these solvents as well as being stable to reduction and oxidation over the potential range to be studied. To be soluble such electrolytes tend to have a large anion or cation (or both), with typical examples being $\mathrm{LiClO}_{4}, \mathrm{LiBF}_{4}$, 
$\mathrm{Hex}_{4} \mathrm{NClO}_{4}, \mathrm{Bu}_{4} \mathrm{NBr}, \mathrm{NaPh}_{4} \mathrm{~B}$. Figure 14 shows how electrical conductivity varies with secondary electrolyte concentration for some organic liquids at $25^{\circ} \mathrm{C}$ [33]. Xu suggested that $10^{-4} \mathrm{~S} \mathrm{~m}^{-1}$ is the lowest conductivity at which quantitative electrochemical measurements can be made usefully in a microelectrode cell [127].

In $2004 \mathrm{Xu}$ synthesised a range of secondary electrolytes based on $\mathrm{R}_{4} \mathrm{~N}^{+} \mathrm{Ph}_{4} \mathrm{~B}^{-}$, with some solubility in esters and hydrocarbons [128], enabling her to investigate the electrochemical behaviour of lubricant additives in these solvents. Oil-soluble ionic liquids are also potential supporting electrolytes and Yang et al. recently reported effects of electrode potential on the ability of solutions of ionic liquids in PC to control friction and wear $[98,99]$.

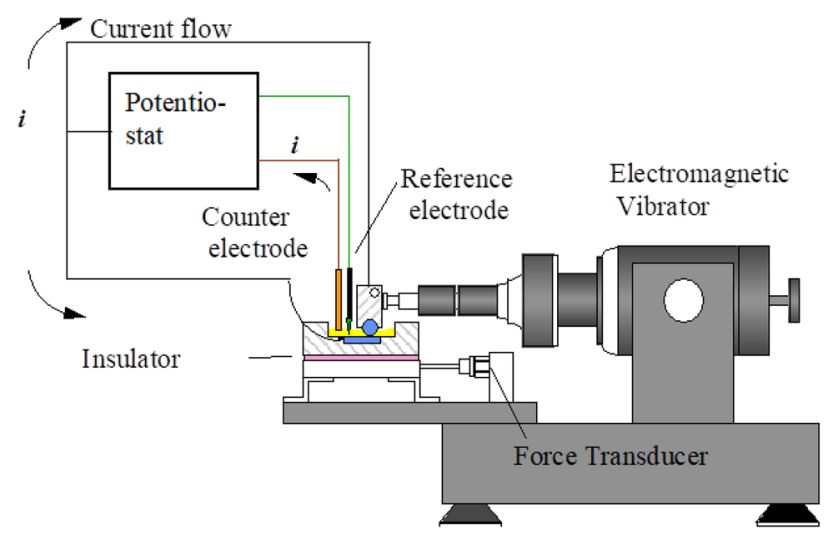

Fig. 15 HFRR with electrolytic cell. Reproduced from [33], with permission from Taylor \& Francis

\subsection{Micro- and Nanoelectrodes}

The resistance of a fluid film separating two parallel electrode surfaces varies inversely with the gap between the surfaces, $d$, i.e. the thickness of the film, so one way to reduce the resistance of the film, and thus the ohmic potential drop is to reduce this gap. However, another, complementary approach is to make the working electrode very small, since this will decrease the current, so decreasing ohmic potential drops as well as overcoming issues of relatively slow diffusion in viscous liquids [127]. In practice it is often easier to fabricate sub-micrometre diameter electrodes than to produce a sub-micron gap; hence, micro-electrodes based on the flat ends of wires of diameter 0.1 and 10 microns are widely used in non-aqueous electrochemical systems. In the 1980s, ultra-microelectrodes were developed and more recently nano-electrodes have become quite widely used. In 2000 Zhu combined an AFM with an electrochemical cell to study the behaviour of solutions of fatty acid in PC under electrode potential control [33]: nowadays electrochemical cells are available as attachments to many commercial AFMs.

\subsection{Three-Electrode Systems in Non-aqueous Lubricants}

The development of supporting electrolytes able to dissolve in organic liquids to raise their electrical conductivity into the $10^{-4}$ to $1 \mathrm{~S} \mathrm{~m}^{-1}$ range was the key to enabling fundamental research on lubricant and lubricant additive behaviour under electrode potential control. This has been applied in two way: (i) to study lubricant additive response to electrode potentials using electrochemical kinetic techniques; (ii) to

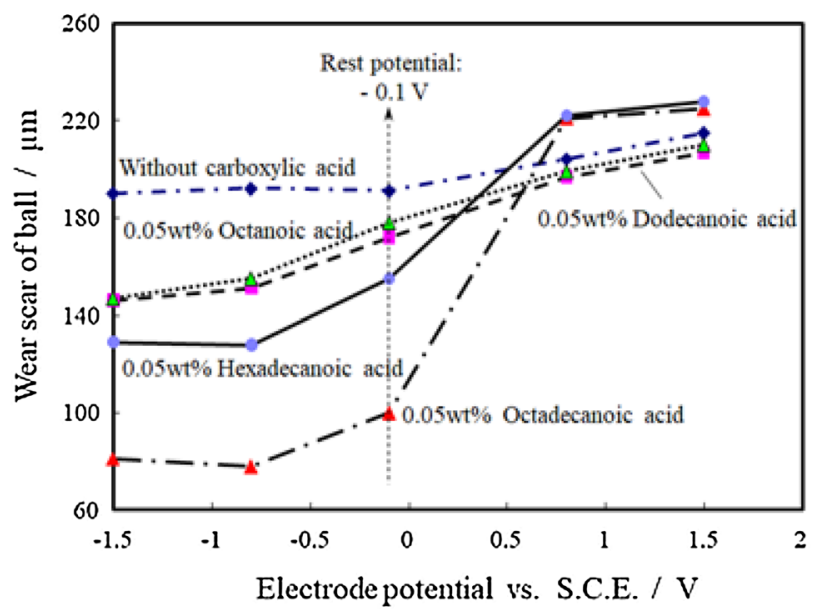

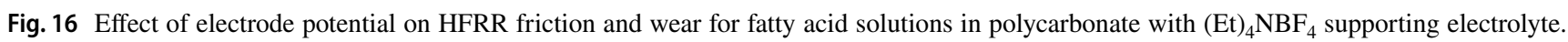
Reproduced from [33], with permission from Taylor \& Francis 
study the effect of electrode potentials on the ability of lubricants to reduce friction and wear.

Initial research focussed on applying conventional electrochemical methods including cyclic voltammetry to study the behaviour of ZDDP in solutions in polar organic solvents [30, 32, 81-83]. The primary interest was the role of ZDDP as an antioxidant, although Ozimina et al. also carried out parallel 4-ball wear measurements with ZDDP solutions [63], while Jacob et al. used ex situ AFM to image the film formed [30]. Blankespoor found that at highly positive potential ZDDP in AN was oxidised to the disulphide, although a secondary ZDDP was then oxidised further Based on a study of ZDDP in DMF, Stereryanskii et al. proposed a dissociation reaction to form the DDP anion which then dimerised to the disulphide [82];

$\left[(\mathrm{RO})_{2} \mathrm{PS}_{2}\right]_{2} \mathrm{Zn} \rightarrow(\mathrm{RO})_{2} \mathrm{PS}_{2}{ }^{-}+\left[(\mathrm{RO})_{2} \mathrm{PS}_{2}\right] \mathrm{Zn}^{+}$

$(\mathrm{RO})_{2} \mathrm{PS}_{2}^{-} \rightarrow(\mathrm{RO})_{2} \mathrm{PS}_{2}^{\cdot}+\mathrm{e}^{-}$

$(\mathrm{RO})_{2} \mathrm{PS}_{2}^{\cdot}+(\mathrm{RO})_{2} \mathrm{PS}_{2} \cdot \rightarrow\left[(\mathrm{RO})_{2} \mathrm{PS}_{2}\right]_{2}$

Ozimina [83] and Jacob [32] focussed on cathodic reactions. Using AFM Jacob identified small nodules of $\mathrm{Zn}$ formed on the electrode by ZDDP in DMF, while Ozima studied a range of metal DDPs in AN, and found that their 4-ball wear behaviour correlated with the ease with which they were reduced to metal.

In $2002 \mathrm{Xu}$ et al. studied the electrochemistry of ZDDP in diethyl-sebacate with $\mathrm{LiClO}_{4}$ as supporting electrolyte [84]. Like Stereryanskii they found disulphide formation under oxidative conditions, and this correlated with decreased

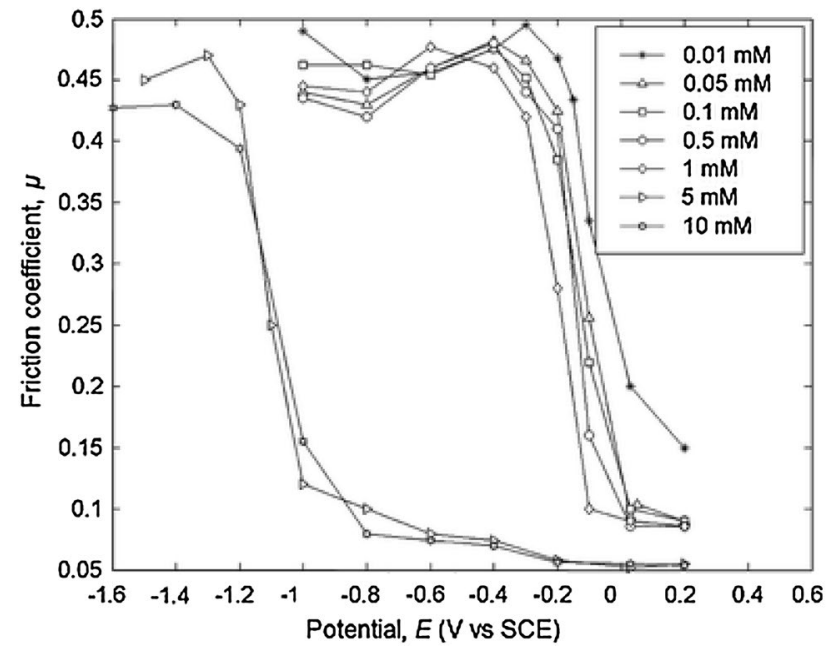

Fig. 17 Dependence of friction on applied solution for sodium dodecyl sulphate solution in water. Reproduced from [88], with permission from Springer Nature friction and wear. This work was extended in 2007 using a more effective secondary electrolyte and both platinum and iron working electrodes [35]. The authors identified oxidation of iron followed by that of ZDDP as the electrode potential was increased.

In all of this research it was found that the ZDDP oxidation reaction was irreversible, with an insoluble product forming on the anode, which made it difficult to perform more than one or two voltammetric cycles. This highlights a limitation of the approach which is that ionic species formed during redox reactions will tend to be insoluble in non-aqueous liquids and, unless removed physically, will tend to block the electrochemical processes.

A possibly more fruitful approach has been to study the influence of electrode potential on friction and wear in three-electrode systems. As the surfaces are rubbing this (i) may remove tribofilms enabling electrochemical, processes to continue or (ii) allow other drivers of film formation to proceed in parallel, so, for example the electrode potential may influence adsorption but the tribochemical reaction be driven by the rubbing action itself.

In $2000 \mathrm{Zhu}$ et al. used a three-electrode system in a high frequency reciprocating rig (HFRR) as shown in Fig. 15 to measure the influence of potential on friction and wear of lubricant additives including fatty acids and dibenzyldisulphide in non-aqueous solvents [33].

Figure 16 shows how friction and wear of iron on iron varied with electrode potential for a series of fatty acids in $\mathrm{PC}$ solution with $(\mathrm{Et})_{4} \mathrm{NBF}_{4}$ supporting electrolyte. Fatty acids reduced friction and wear only at negative potentials and friction decreased with increasing chain length. Electrochemical impedance spectroscopy also indicated the presence of a 5-10 nm film at negative potentials but negligible film was formed under oxidising potentials. In interpreting these results, it is important to note that the friction coefficient values at negative potentials were close to those expected in the absence of an applied potential, suggesting that friction and wear were simply those prevalent at the rest potential $(-0.1 \mathrm{~V}$ as marked with a dotted line). Thus it appears that the friction-reducing effect of the fatty acids was not improved by applying negative potentials, but rather diminished by positive electrode potentials. This may reflect fatty acid molecules not adsorbing well on positively charged surfaces, or the iron being oxidised and the fatty acid forming a metal carboxylate that was not an effective friction modifier in HFRR conditions. Briscoe et al. have found considerable differences between the friction properties of fatty acids and fatty acid metal soaps [129]. It is interesting to note that the wear actually increased to a value higher than that of the solvent for long chain fatty acids at oxidising electrode potentials. Long chain fatty acids are more soluble in organic solvents than short chain counterparts and this may reflect corrosive wear resulting from the 
formation of semi-soluble iron carboxylates followed by their dissolution.

This dependence on electrode potential is in interesting contrast to studies in aqueous solution by Brandon et al. [62], Zhu et al. [64] and recently by He et al. [88] who found friction to decrease sharply at positive electrode potentials for surfactant solutions. The latter is shown in Fig. 17 and was ascribed by the authors to a threshold of adsorption of negatively charged sulphate anions on the surfaces [88].

Ogano used as working electrode the steel ball in a ball on glass disc optical rig and employed optical interferometry to measure the effect of electrode potential on film thickness $[21,130]$. He found that an oxidising electrode potential promoted thick boundary film formation by hexadecanoic acid solution in PC at low sliding speeds. In conjunction with HFRR results this may suggest that, while a frictionreducing, adsorbed monolayer forms at reducing electrode potentials, at oxidising potentials a semi-soluble salt is formed that cannot withstand severe boundary lubrication conditions but does contribute to enhanced entrainment in rolling-sliding conditions.

Three-electrode equipment has also been employed to study the friction and wear properties of antiwear and extreme pressure additive behaviour. Zhu et al. used the HFRR apparatus shown in Fig. 15 to study the effects of applied potential on dibenzyldisulphide (DBDS) solution on $\mathrm{DEA} / \mathrm{LiClO}_{4}$ [33]. They found that the DBDS was effective at reducing wear only at highly negative electrode potentials and, by combining this with results from cyclic voltammetry, suggested that under this condition the disulphide was reduced to a benzylsulphide radical that then reacted with the reduced iron surface to form iron mercaptide. By contrast $\mathrm{Xu}$ et al. found that ZDDP was most effective at highly oxidising electrode potentials, at which voltammetry showed that it formed the disulphide [35, 127]. ZDDP was moderately effective in decreasing wear at all potentials, so the authors suggested that this indicated that its reaction to form tribofilms was not primarily electrochemical in nature [35]. In 2018, a similar study by Cao and Meng of ZDDP solutions in a blend of PC and diethylsuccinate also found friction and wear to be decreased at oxidising potentials [89].

\section{Applications of Triboelectrochemistry}

\subsection{Aqueous Lubricants}

The primary practical application of applied electrical potentials in aqueous systems to date has been to the field of material cutting and polishing, including electrolytic grinding (ELG) [131], triboelectrochemical polishing (TEMP) [132], electrolytic in-process dressing (ELID) [133] and electrochemical-mechanical polishing (ECMP) [134]. In ELG and ECMP the metal workpiece is made the anode so that applied oxidising potentials produce metal oxides that are easily removed by abrasion. In ELID and TECP the workpiece is non-conducting but the polishing tool contains a metal, and so is conducting. In ELID an applied potential difference oxidises transferred metal that would otherwise reduce the effective wheel roughness, while in TEMP it forms an oxide to modify the pad's polishing properties.

It has also been suggested that applied electrical potentials may be used to prevent corrosive damage to cutting tools [135], reduce torque at the drilling mud-drill string interface [136], help release stuck drill-pipes [137], reduce energy consumption in wire drawing [120, 121], improve chemical mechanical planarisation of microelectronic wafers [9] and even reduce plough/soil friction [138]. There are, no doubt others, but the extent to which any of these have been implemented in practice is not clear.

\subsection{Non-aqueous Lubricants}

To date, the practical application of applied electrode potentials to oil-based systems has been almost entirely towards measuring and monitoring film thickness and oil degradation and contamination rather than towards control of tribological performance.
Fig. 18 Impedance spectra for fresh and oxidized oils measured at $120^{\circ} \mathrm{C}$. Reproduced from [42], with permission from Elsevier

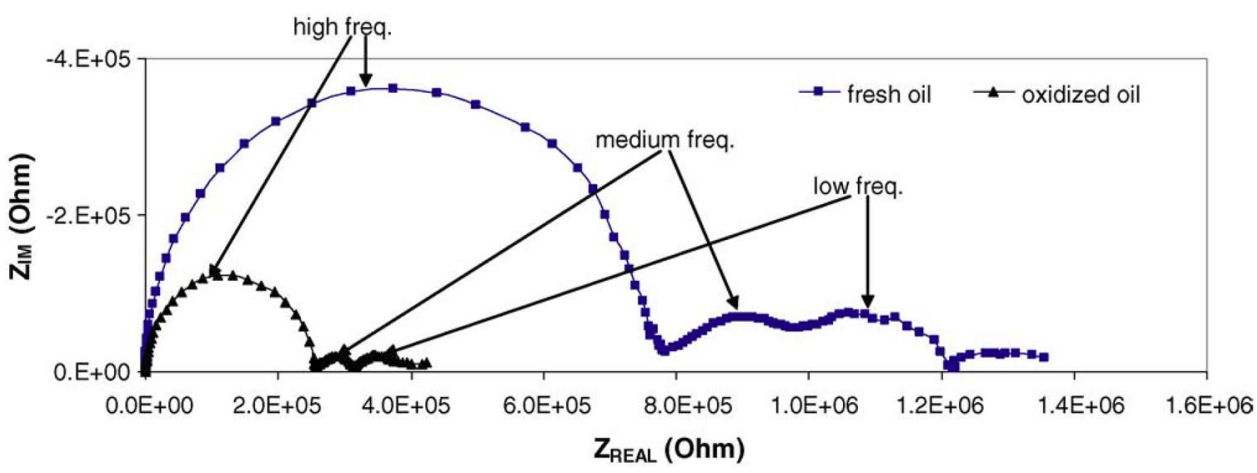


In the 1980s, Kauffman and Rhine developed a remaining useful life of a lubricant evaluation technique (RULLET) based on cyclic voltammetry [139-141]. In this, extracted oil samples were diluted with acetone-containing electrolyte $\left(\mathrm{LiClO}_{4}\right)$ and organic base, in which a Pt electrode was used for cyclic voltammetry. They showed that the technique was capable of performing formulation-independent remaining useful life evaluations of used gas turbine engine lubricating oils and a commercial remaining useful life evaluation rig (RULER) was designed. This method estimates primarily the amount of antioxidant remaining in the lubricant and is now the basis of several ASTM standards [142-144].

The second main application area has been to monitor the degradation and contamination of lubricants by measuring their electrical impedance. Since the resistance of a lubricant decreases with the presence of polar contaminants, while its capacitance tends to increase, in recent years such measurements have become a valuable way to assess of the extent of degradation of lubricants [145-148]. In practice the approach can be applied at various levels of complexity, with perhaps the simplest being just to compare the tangent of the phase shift, $\tan \delta$ (the ratio of real to imaginary components of the impedance) of a used oil with that of the fresh lubricant at a chosen AC frequency [149]. By contrast, in electrochemical impedance spectroscopy (EIS), impedances are measured between two Pt electrodes over several decades of AC frequency [42]. Figure 18 shows impedance spectra in the form of Nyquist plots of a fresh and an oxidised industrial lubricant in a cell [42]. After oxidation, both resistance and reactance decrease. In this study high frequency spans $10 \mathrm{MHz}$ to $10 \mathrm{~Hz}$, medium frequency $10 \mathrm{~Hz}$ to $0.1 \mathrm{~Hz}$ and low frequency $100 \mathrm{mHz}$ to $1 \mathrm{mHz}$. The responses at different frequencies correspond to various components in the oil responding with different time constants; in this case polarisation of molecular dipoles, adsorption on surfaces and diffusion processes, respectively. The authors proposed a quite complex equivalent circuit based on a series of parallel capacitors and resistors to represent the cell.

The electrical capacitance of a lubricant film depends on its dielectric constant and originates from the polarisability of the molecules therein contained. In general, the larger the concentration of polar species such as water, ethanol and oxidation products, the greater the dielectric constant and thus the capacitance. However, dielectric constant also varies with AC frequency and the variation of dielectric constant of a lubricant with frequency can provide information about the concentration and rotational mobility of its polar and polarisable molecules. The study of how dielectric constant varies with frequency is termed dielectric spectroscopy (DES) [150], which can be used to characterise base oil composition as well as oil degradation [151-153]. In practice, EIS and DES are closely related.
EIS and simpler types of electrical impedance measurement are potentially powerful tools for monitoring lubricant degradation, with the ability to monitor various forms of lubricant contamination [154-156]. While they can be used off-line [157], primary interest in recent years has been to develop on-line sensors that can monitor oil degradation in operating machinery and engines, e.g. [149, 158-164]. Their main practical limitation lies in difficulty of interpretation, since most lubricants are complex blends of polar additives that even without degradation provide a complicated impedance spectrum, which can be interpreted fully only if the formulation composition is already known. The addition of ill-defined degradation products such as oxidation products adds to this complexity so that some developers are applying machine-learning and other expert systems to interpret and correlate electrical measurements with lubricant composition $[152,153]$. While this difficulty of interpretation limits the value of EIS and related measurements as research tools to study lubricants per se, it does not detract from their value as empirical ways to monitor changes in lubricant electrical properties resulting from ageing during use and that provide a measure of lubricant condition.

The above are not strictly applications of triboelectrochemistry since they are not concerned with understanding or controlling the impact of applied potential on tribological performance. One suggested application that does meet this criterion is the use of applied electrode potentials to actively control friction of rubbing contacts. Control of tribological performance using electronics has been given the name tribotronics [165]. In the context of triboelectrochemistry it is proposed that the rapid response of boundary friction to applied potential can be employed to provide active feedback to maintain desired friction values under the changing conditions present in many lubricated contacts. To date only highly idealised systems based on neat ionic liquids and ionic liquid solutions in AFM contacts have been studied $[103,105]$

\section{Discussion}

\subsection{Adsorption Versus Reaction}

From the above review it appears that, except at very low loads at which electrostatic repulsion may be significant in decreasing the effective contact pressure, applied electrical potential can influence friction in wear in two main ways: (i) by driving redox reactions that promote or suppress the formation of tribochemical films and (ii) by altering the charge of rubbing surfaces so as to encourage or hinder adsorption of tribologically active, polar additives.

Historically most research has tended to focus on the first of these mechanisms. In aqueous systems the main interest 
has been in using applied electrode potential to oxidise or reduce rubbing metal surfaces so as directly to change friction and wear properties or, at least aspirationally, to alter the way that the surfaces interact with additives. In nonaqueous systems, most interest has been in controlling the reaction of additives such as ZDDP, both to help determine the reaction paths by which these additives form tribofilms and also to provide active control of additive response. In the authors' view the practical value of the former may be quite limited since it is questionable whether the route by which additives react to form tribofilms under applied electrode potential conditions is the same as that which occurs during rubbing in the absence of applied potentials. Non-aqueous electrochemical measurements have focussed mainly on ZDDP solutions and have shown that these form the disulphide under oxidising electrode potentials. Using NMR analysis some disulphide has been identified in strongly heated ZDDP solutions [166], but this route is not generally considered to be involved in tribofilm formation, although the disulphide is formed when ZDDP acts as an antioxidant [167].

In terms of providing active control of additive reactions, applied potentials have been shown to influence friction and wear of lubricant additive-containing solutions but to date only a very limited number of additives, primarily fatty acids $[33,62]$, organosulphate salts [34, 88, 99], ZDDP [33, 35, 89] and DBDS [127] have been studied in this way. Perhaps this is surprising since outside of tribology a series of studies by Dubois et al. has shown that applied electrode potentials can control the reaction of many chemicals at surfaces, including polymerisation of acetate to polyethylene [168], acrolein to polyacrolein [169] phenols to polyphenyl oxides [170] and anilines and vinylcarbazoles to organic polymers [171, 172]. The main aims of Dubois's research were to explore the underlying polymerisation processes and to develop ways to form thin (sub $100 \mathrm{~nm}$ ) organic films on surfaces for electronic devices, so it was not directed deliberately towards tribology. However in much of the work, film formation was monitored by measuring changes in friction coefficient.

Several researchers have studied the influence of applied electrode potentials on the adsorption of surfactants, primarily in the context of detergency and flotation [173-178], but only recently have the possibilities of using this to control friction been clearly recognised [88]. Most friction studies have been in aqueous systems, but quite recently the friction properties of solutions of ionic liquids in non-aqueous solvents have been shown to depend on applied potential due to adsorption of their cations (at reducing potentials) and anions (at oxidising potentials) [98, 99, 105]. In some ways, the use of applied potentials to actively control friction and wear by promoting adsorption might be more practicable than its use to promote chemical reactions, since the former may be reversible and also likely to require lower potentials. However the amount of research in non-aqueous systems to date specifically aimed at the effects of applied electrode potential on adsorption, and thus friction, is quite limited.

\subsection{Two-Electrode Versus Three-Electrode Electrochemical Measurements}

It should be evident from this review that in non-aqueous triboelectrochemistry research, there is a something of a disconnect between early research that simply applied a potential difference across a rubbing contact (a two-electrode system) and more recent research based on three-electrode systems. In the latter the potential difference between surface and fluid can be controlled relative to a suitable reference electrode and the same potential can be applied to both tribo-surfaces. However, to be applicable to organic lubricants, this approach has required the use of secondary electrolytes to raise the electrical conductivity and/or the use of microelectrodes. While three-electrode systems may be valuable to establish how lubricated contacts respond to applied potentials, it is difficult to envisage how they may (a)

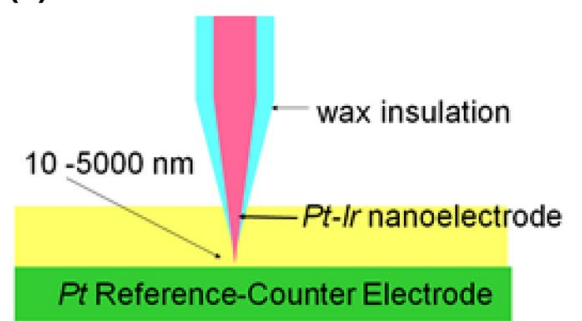

Fig. 19 a STM/substrate system used to explore influence of electrode gap on cyclic voltammetry. b Current/potential behaviour of $\mathrm{Pt} / 0.045 \mathrm{M}$ ferrocene + $0.022 \mathrm{M}$ DBDS in 20\% DEA and $80 \%$ hexa-

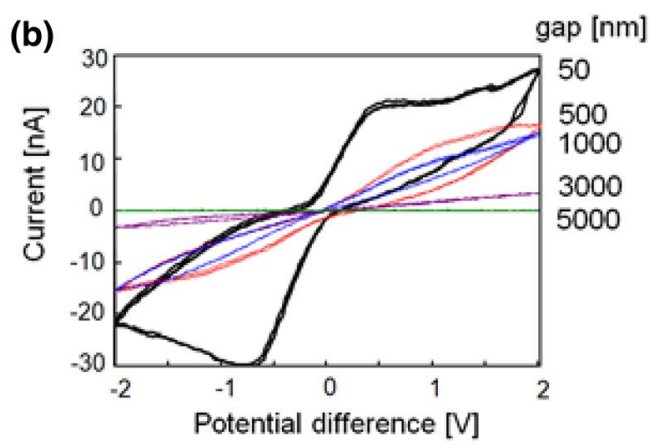

decane with $0.001 \mathrm{M} \mathrm{LiClO}_{4} / \mathrm{Pt}$-Ir tip as a function of substrate/tip gap. Scan rate $=1 \mathrm{~V} / \mathrm{s}$, temperature $=25^{\circ} \mathrm{C}$. Reproduced from [33], with permission from Taylor \& Francis 


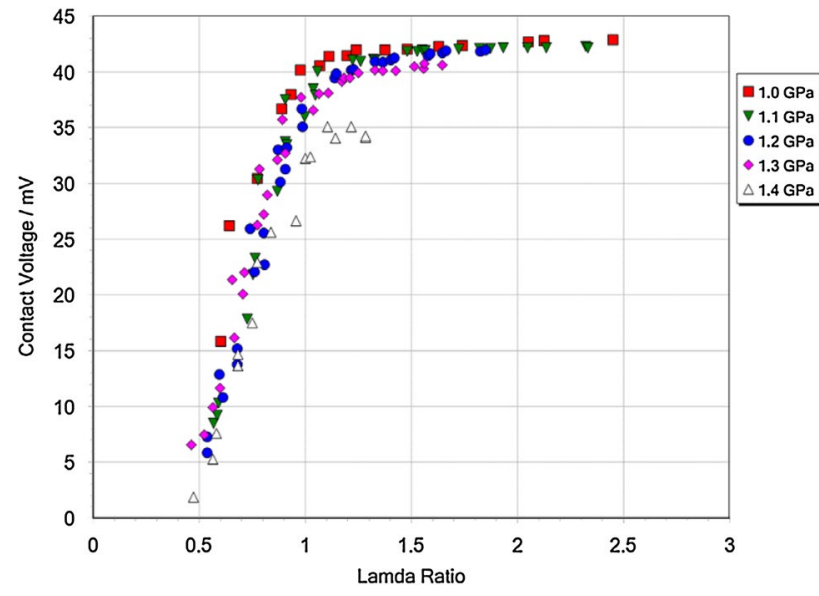

Fig. 20 Effect of lambda ratio on mean contact voltage. Reproduced from [182], with permission from Elsevier

be applied to macro-scale, oil-based lubricated contacts present in actual machine components. Very few secondary electrolytes are soluble in hydrocarbon-based lubricant and those that are tend themselves to be surfactant-like and thus likely to adsorb and block access of other additives to the surface. Also most practical lubricated components are of macro rather than micro-scale dimensions.

One key question that then arises is the extent to which two-electrode systems, in which a potential is applied directly across the two electronically conducting surfaces of a lubricated rubbing contact, possibly informed from threeelectrode measurements, may be feasible and useful in terms of controlling additive behaviour and thus friction and wear. In such contacts, at least where boundary friction and wear are of practical importance, the gap between rubbing surface is in the range $1 \mathrm{~nm}$ to $10 \mu \mathrm{m}$, which should ensure a relatively low resistance and thus low ohmic potential drop. The limited amount of such work carried out in the 1970s to 1990 s certainly indicates that lubricant behaviour can be influenced by applied potential, but unfortunately this work tended to be quite empirical and contact conditions were rarely well-defined.

Zhu et al. studied the influence on cyclic voltammetry of the gap between a working electrode and counter electrode using a nanoelectrode arrangement based on an AFM [33]. As shown in Fig. 19a, the working electrode was a Pt/ Ir scanning tunnelling microscope (STM) tip and this was positioned against a Pt substrate counter/reference electrode, with a gap distance ranging from 5000 to $50 \mathrm{~nm}$. The electrolyte was a mixture of ferrocene and DBDS dissolved in a blend of hexadecane and ester, with $\mathrm{LiClO}_{4}$ as supporting electrolyte. The ester was present to ensure solubility of the $\mathrm{LiClO}_{4}$ and ferrocene and DBDS were used together to provide both oxidisable and reducible species. Figure 19b shows how the cyclic voltammograms varied with tip/ substrate spacing. It is evident that useful voltammograms can be acquired when the gap is $1 \mu \mathrm{m}$ or less and that with a gap of $50 \mathrm{~nm}$ excellent response curves are obtained.

These results used a $\mathrm{LiClO}_{4}$ supporting electrolyte, but Zhu et al. also showed that cyclic voltammograms could be obtained without any electrolyte with a $50-\mathrm{nm}$ gap. This suggests that it should be possible to control additive reactions in thin film conditions so long as separating films at asperities are less than about $100 \mathrm{~nm}$. Clearly it is not possible to establish a significant potential difference across the surfaces if the fluid film resistance is too low, as would occur if there were effective contact between asperities or the fluid film experienced dielectric breakdown. Kawamura has suggested that electron tunnelling, and thus effective contact, is negligible for film thickness above $0.5 \mathrm{~nm}$ and that dielectric breakdown under the application of an applied voltage of $0.1 \mathrm{~V}$ will only occur when the oil film thickness is $<2 \mathrm{~nm}$ [179]. Thus, even a very thin separating should enable useful potential differences to be maintained.

Several studies have explored the electrical contact resistance across sliding and rolling-sliding lubricated contacts and how this evolves as entrainment speed and thus lubricant film thickness increases [180-186]. These have all shown a transition from almost continuous contact and low resistance in very thin film conditions, through intermittent episodes of negligible resistance (shorting) due to asperity contact at intermediate film thickness, to reach continuous high resistance under high speed, thick film conditions. A few studies have also carried out parallel film thickness measurements and related the fraction of time that contact resistance is negligible to the lambda ratio (ratio of film thickness to surface roughness) [181, 182]. Figure 20 shows the effect of lambda ratio on the mean contact potential difference between two gear teeth. In this system there was effective switching between the applied voltage value of $0.043 \mathrm{~V}$, when full separation occurred, and zero when there was continuous asperity contact, so the mean value was a measure of the fraction of time during which there was asperity contact.

It is evident from Fig. 20 that even with rough gear contacts $(R a=400 \mathrm{~nm})$ a potential difference can be established across the lubricated contact except at very low lambda ratios. Of course, once a tribofilm starts to develop on the rubbing surfaces the electrical contact resistance should no longer fall to zero in boundary film conditions, in which case a continuous potential difference can be applied.

The second problem of applying a potential difference across a lubricated contact to control friction or wear, as mentioned in Sect. 2.1 of this review, is that it inevitably subjects the two rubbing surfaces to different potentials, one positive and the other negative. This means that for a pair of surfaces with the same metallurgy, any adsorbed or reacted film driven by applied electrode potential will only be formed on one of the surfaces. Yamamoto and Hirano 
noted that to prevent scuffing with an oil containing the additive tricresyl phosphate it was preferable to apply an oxidising potential to the surface that was always in contact and thus experienced more severe rubbing conditions [36]. However it was also important not to apply too large a negative, reducing potential to the surface that moved relative to the contact so as to allow some tribochemical film formation on this surface.

Other ways can be envisaged to address this problem but do not appear yet to have been studied. One, applicable to the control of adsorption by applied electrode potential, might be to use zwitter-ion OFMs able to carry both positive and negative change, as indicated in the early work of Staicopoulos [51]. Alternatively, mixtures of OFMs or antiwear additives containing different molecules able to adsorb and/ or react on positive and negatively charged surfaces might be employed. Another approach, relevant to the systems in which applied potential stimulates reaction of additives to form surface films, might be to switch between oxidising and reducing electrode potentials periodically so as to stimulate the desired reaction on one surface and then the other intermittently.

Based on the above the author considers that further work on the application of electrical potentials across contacts might prove fruitful, especially if combined with three-electrode studies to identify the main redox and adsorption processes possible. Two-electrode work carried out in the 1970s to 1990s was largely empirical and, with the exception of that of Yamamoto and Hirano [36], studied poorly defined base oils or formulated oils. There is clear scope for revisiting this approach using modern methods of surface analysis and experimentation, including AFM.

\subsection{Ionic Liquid Additives}

An important development in recent years that has already been noted in this review is the growing interest in room temperature ionic liquids as base fluids $[187,188]$ and as lubricant additives [189]. In the former role they possess extremely low volatility and high thermal stability, while in the latter they have shown some promise in reducing friction and wear. Many publications have reported electrical conductivities of pure ILs and these range from more than $1 \mathrm{~S} \mathrm{~m}^{-1}$ down to ca $10^{-4} \mathrm{~S} \mathrm{~m}^{-1}$, depending on the sizes of the anions and cations and viscosities [190, 191]. It has been suggested that a key property may be the mobility of the free ions or "ionicity", so that ionic liquids in which the anions and cations remain closely associated have lower ionic conductivities [190]. However, few publications have reported electrical conductivities of solutions of ionic liquids in dielectric fluids such as lubricant base oils. Somers et al. measured values of ca $10^{-5}$ and $10^{-7} \mathrm{~S} \mathrm{~m}^{-1}$ for two phosphorus-based ionic liquids in solution in mineral oil [192] while Yang et al. found that solutions of $5 \times 10^{-4} \mathrm{M}$ imidazoline-based ionic liquids raised the conductivity of propylene carbonate from less than $3.10^{-6} \mathrm{~S} \mathrm{~m}^{-1}$ to about $10^{-3} \mathrm{~S} \mathrm{~m}^{-1}$, so enabling electrochemical measurements in these solutions.

The practical limitation of using ionic liquids to increase electrical conductivities of lubricants is that the factors that enable these to be soluble in non-polar base fluids, i.e. a high organic content and large size, also tend to lead to decreased ionicity and thus low electrical conductivities. However, it is possible that ionic liquids may raise the conductivity of hydrocarbon and ester-based oils enough to enable triboelectrochemical effects be driven by applied potentials differences across rubbing contacts. This may be an opportunity but, of course, also a risk if the driving potentials are inadvertent rather than being deliberately applied.

Finally, it should be mentioned that although most lubricants are based on organic base fluids with low electrical conductivities, and in particular on hydrocarbons, some are water-based, including water-in-oil and oil-in-water emulsions and polymer-thickened aqueous solutions. In the past these have been used primarily as metal forming and hydraulic fluids and their ability to lubricate concentrated contacts has been reported to be quite limited [193], but recently water-based transmission lubricants have been proposed and developed [194-196]. The potential application of the triboelectrochemical research outlined above to such fluids should be manifest.

\section{Conclusion}

This paper has reviewed past research on the effects of applied electrical potentials on friction and sliding wear, a topic sometimes termed "Triboelectrochemistry". Historically most research has focussed on aqueous lubricants, whose relatively high electrical conductivity means that classical three-electrode electrochemical methods, where the potential at the surface/fluid interface is closely controlled, can be employed. This has identified several different mechanisms by which applied potentials can influence friction and wear. Of these the most practically important appear to be; (i) promotion of adsorption/desorption of polar additives on tribological surfaces by controlling the latters' surface charge; (ii) stimulation or suppression of redox reactions at rubbing surfaces involving either oxygen in air or lubricant additives.

In recent years there has been growing interest in the effects of applied electrode potentials on rubbing contacts lubricated by non-aqueous lubricants such as ester- and hydrocarbon-based oils. Here there have been two different 
approaches. One has been simply to apply DC voltages directly across thin film, lubricated contacts. Such applied voltages, in the $\mathrm{mV}$ to $\mathrm{V}$ range, have been found to promote some additive reactions and to influence friction and wear, although little systematic exploration of the underlying processes involved has been carried out and generally the potential difference at the interface between lubricant and surfaces has not been well-defined. The second approach is to increase the conductance of non-aqueous lubricants by using micro/nanoscale electrodes and/or secondary electrolytes, to the extent that classical electrochemical three-electrode methods can be employed. This work has revealed some underlying mechanisms but probably has limited application in real lubricated components. The authors consider that combination in parallel of the two approaches; one to provide fundamental understanding and the other applicable to actual tribological systems would be a fruitful approach.

A recent development has been the introduction of ionic liquids as both base fluids and lubricant additives. These have relatively high electrical conductivity and this provides enhanced electrochemical response to applied potentials. The broadening use of "green", aqueous-based lubricants also enlarges the possible future scope of applied potentials to tribology.

It is important to note that the impact of applied potentials on friction and wear in lubricated systems may be beneficial or harmful. If inadvertent and inappropriate they may enhance friction and increase wear, for example by supressing adsorption of additives on surfaces, oxidising rubbing surfaces rapidly or even generating undesirable species such as hydrogen. However if deliberate and wellchosen they may lead to more effective tribofilm formation, "smart" friction control or suppression of undesirable processes such as corrosive wear. It is evident that, based on this review there is a need for considerable further research to explore the impact of applied potentials on lubricant-surface interactions and thereby on friction and wear.

Acknowledgements The author thanks Professor Geoff Kelsall for his generous advice during preparation of this review.

Open Access This article is licensed under a Creative Commons Attribution 4.0 International License, which permits use, sharing, adaptation, distribution and reproduction in any medium or format, as long as you give appropriate credit to the original author(s) and the source, provide a link to the Creative Commons licence, and indicate if changes were made. The images or other third party material in this article are included in the article's Creative Commons licence, unless indicated otherwise in a credit line to the material. If material is not included in the article's Creative Commons licence and your intended use is not permitted by statutory regulation or exceeds the permitted use, you will need to obtain permission directly from the copyright holder. To view a copy of this licence, visit http://creativecommons.org/licenses/by/4.0/.

\section{References}

1. Edison, T.A.: Improvement in telegraph apparatus. US Patent No. 158,787 (1875)

2. Edison, T.A.: The electromotograph: a new discovery in telegraphy. Sci. Am. 31, 145 (1874)

3. Edison, T.A.: The storage battery and the motor car. N. Am. Rev. 175, 1-4 (1902)

4. Waterhouse, R.B.: Tribology and electrochemistry. Tribology. 3, 158-162 (1970). https://doi.org/10.1016/0041-2678(70)90113-2

5. Guruswamy, V., Bockris, J.O.: Triboelectrochemistry. In: Bockris, J.O., Conway, B.E., Yeager, E., White, R.E. (eds.) Comprehensive Treatise of Electrochemistry, pp. 463-471 (1980)

6. Lvovich, V.F.: Chapter 10. Selected examples of EIS analysis applications: industrial colloids and lubricants. In: Impedance Spectroscopy: Applications to Electrochemical and Dielectric Phenomena, pp. 219-246 (2012)

7. Xie, G., Guo, D., Luo, J.: Lubrication under charged conditions. Tribol. Int. 84, 22-35 (2015). https://doi.org/10.1016/j.tribo int.2014.11.018

8. Jiang, Z.Q., Fang, J.H., Chen, Y.C., Wu, J., Liu, P., Gu, K.C., Zheng, Z., Chen, B.S., Wang, X., Feng, Y.H.: A review of lubricating mechanisms from the perspective of tribo-electrophysics and tribo-electrochemistry. Sci. China Technol. Sci. 6, 1244 (2018). https://doi.org/10.1007/s11431-017-9291-3

9. Krim, J.: Controlling friction with external electric or magnetic fields: 25 examples. Front. Mech. Eng. 5, 22 (2019). https://doi. org/10.3389/fmech.2019.00022

10. Prashad, H.: Effect of operating parameters on the threshold voltages and impedance response of non-insulated rolling element bearings under the action of electrical currents. Wear 117, 223-240 (1987). https://doi.org/10.1016/0043-1648(87)90257-2

11. Prasad, H.: Tribology in electrical environments. Lubr. Sci. 13, 359-369 (2001)

12. Beck, T.R.: Wear by generation of electrokinetic streaming currents. ASLE Trans. 26, 144-150 (1983). https://doi. org/10.1080/05698198308981488

13. Krantz, J., Tuomas, R., Bhushan, B.: Electrorheological fluids for lubrication. Lubr. Eng. 55, 28 (1999)

14. Xie, G., Luo, J., Liu, S., Zhang, C., Lu, X.: Micro-bubble phenomenon in nanoscale water-based lubricating film induced by external electric field. Tribol. Lett. 29, 169-176 (2008). https:// doi.org/10.1007/s11249-007-9288-8

15. Xie, G., JianBin, L., Dan, G., ShuHai, L., Gang, L.: Damages on the lubricated surfaces in bearings under the influence of weak electrical currents. Sci. China Technol. Sci. 56, 2979-2987 (2013). https://doi.org/10.1007/s11431-013-5399-7

16. Burgo, T.A.L., Silva, C.A., Balestrin, L.B.S., Galembeck, F.: Friction coefficient dependence on electrostatic tribocharging. Sci. Rep. 3, 1-8 (2013). https://doi.org/10.1038/srep02384

17. Ciniero, A., Fatti, G., Righi, M.C., Dini, D., Reddyhoff, T.: A combined experimental and theoretical study on the mechanisms behind tribocharging phenomenon and the influence of triboemission. Tribol. Online. 14, 367-374 (2019). https://doi. org/10.2474/trol.14.367

18. Hamilton, G.M., Moore, S.L.: Measurement of the oil-film thickness between the piston rings and liner of a small diesel engine. In: Proc. Instn. Mech. Engrs. Tribology Group. The Lubrication of Piston Rings. 20/74, pp. 253-261 (1974)

19. Maruyama, T., Nakano, K.: In situ quantification of oil film formation and breakdown in EHD contacts. Tribol. Trans. 61, 1057-1066 (2018). https://doi.org/10.1080/10402 004.2018.1468519

20. Bard, A.J., Faulkner, L.R.: Electrochemical Methods: Fundamentals and Applications, 2nd edn. Wiley, New York (2001) 
21. Ogano, S.: Electrochemical control of friction and wear. $\mathrm{PhD}$ Thesis, Univ. London. (1998)

22. Trasatti, S.: Work function, electronegativity, and electrochemical behaviour of metals. Electroanal. Chem. Interfacial Electrochem. 33, 351-378 (1971)

23. Mccafferty, E.: Relationship between the isoelectric point ( $\mathrm{pH} \mathrm{pzc}$ ) and the potential of zero charge ( E pzc ) for passive metals. Electrochim. Acta 55, 1630-1637 (2010). https://doi. org/10.1016/j.electacta.2009.10.040

24. Abedian, B.: The diffuse double layer in hydrocarbon liquids. Chem. Eng. Sci. 43, 1414-1416 (1988)

25. Washabaugh, A.., Mamishev, A., Du, Y., Zahn, M.: Dielectric measurements of semi-insulating liquids and solids. In: ICDL '96 12th International Conference of Conduction and Breakdown of Dielectric Liquids, Rome, July 15-19, pp. 381-384 (1996)

26. Prieve, D.C., Hoggard, J.D., Fu, R., Sides, P.J., Bethea, R.: Two independent measurements of Debye lengths in doped nonpolar liquids. Langmuir 24, 1120-1132 (2008). https://doi. org/10.1021/la702351e

27. Fowkes, F.M., Jinnai, H., Mostafa, M.A., Anderson, F.W., Moore, R.J.: Mechanism of electrical charging of particles in nonaqueous liquids. In: Hair, M.L., Croucher, M.D. (eds.) Colloids and Surfaces in Reprographic Technology: ACS Symposium Series, pp. 307-324. ACS (1982)

28. Wang, S.S., Maheswari, S.P., Tung, S.C.: The nature of electrochemical reactions between several zinc organodithiophosphate antiwear additives and cast iron surfaces. Tribol. Trans. 32, 91-98 (1989). https://doi.org/10.1080/10402008908981867

29. Zhu, Y., Kelsall, G.H., Spikes, H.A.: Triboelectrochemistry on a nanometre scale. Tribol. Lett. 2, 287-312 (1996). https://doi. org/10.1007/BF00173134

30. Ozimina, D., Scholl, H., Płaza, S.: Electrochemical simulation of friction interactions on the basis of anti-wear behaviour of metallo-dibutyldithiophosphate complexes [(DTP)z Mz+A] in non-aqueous media. Tribol. Lett. 3, 147-155 (1997). https://doi. org/10.1023/A:1019124920583

31. Farrington, A.M., Slater, J.M.: Monitoring of engine oil degradation by voltammetric methods utilizing disposable solid wire microelectrodes. Analyst. 122, 593-596 (1997). https://doi. org/10.1039/a608022g

32. Jacob, S.R., Compton, R.G.: Electrochemical studies of the automotive lubricant additive zinc n-dibutyldithiophosphate. J. Electrochem. Soc. 146, 2598-2605 (1999). https://doi. org/10.1149/1.1391978

33. Zhu, Y., Ogano, S., Kelsall, G.H., Spikes, H.A.: The study of lubricant additive reactions using non-aqueous electrochemistry. Tribol. Trans. 43, 175-186 (2000)

34. Chang, Q., Meng, Y., Wen, S.: Influence of interfacial potential on the tribological behavior of brass/silicon dioxide rubbing couple. Appl. Surf. Sci. 202, 120-125 (2002). https://doi. org/10.1016/S0169-4332(02)00935-2

35. Xu, X., Spikes, H.: Study of zinc dialkyldithiophosphate in di-ethylhexyl sebacate using electrochemical techniques. Tribol. Lett. 25, 141-148 (2007). https://doi.org/10.1007/s1124 9-006-9132-6

36. Yamamoto, Y., Hirano, F.: Scuffing resistance of phosphate esters II: effect of applied voltage. Wear 66, 77-86 (1981). https://doi. org/10.1016/0043-1648(81)90034-X

37. Jiang, H., Wong, P.L., Meng, Y., Wen, S.: An indirect electric field effect on the friction of boundary-lubricated contacts. Lubr. Sci. 15, 275-291 (2003)

38. Radice, S., Mischler, S.: Effect of electrochemical and mechanical parameters on the lubrication behaviour of $\mathrm{Al} 2 \mathrm{O} 3$ nanoparticles in aqueous suspensions. Wear 261, 1032-1041 (2006). https ://doi.org/10.1016/j.wear.2006.03.034
39. Ismail, M.N.F., Harvey, T.J., Wharton, J.A., Wood, R.J.K., Humphreys, A.: Surface potential effects on friction and abrasion of sliding contacts lubricated by aqueous solutions. Wear 267, 1978-1986 (2009). https://doi.org/10.1016/j.wear.2009.06.007

40. Barsoukov, E., Macdonald, J.R.: Impedance Spectroscopy Theory, Experiment, and Applications, 2nd edn. Wiley-Interscience, Hoboken, N.J (2005)

41. Naerheim, Y., Kendig, M.: Evaluation of cutting fluid effectiveness in machining using electrochemical techniques. Wear 114, 51-57 (1987). https://doi.org/10.1016/0043-1648(87)90015-9

42. Lvovich, V.F., Smiechowski, M.F.: Impedance characterization of industrial lubricants. Electrochim. Acta. 51, 1487-1496 (2006). https://doi.org/10.1016/j.electacta.2005.02.135

43. Edison, T.A.: un appareil connu sous le nom d'electro-motograph. Compte Rendus Acad. des Sci. Paris. 87, 270-271 (1878)

44. Koch, K.R.: Ueber die Verärndeung, welche die Oberfläche des Platins und des Palladiums durch die Sauerstoffpolarisation erfährt. Ann. Phys. 244, 92-97 (1879)

45. Waitz, K.: Ueber den Einfluss der galvanischen Polarisation auf die Reibung. Ann. Phys. 256, 285-303 (1883)

46. Rehbinder, P., Wenstrom, E.: Sur les effets electrocapillaires de reduction de la rigidite et de la durete des metaux. Acta Physicochim. U.R.S.S. 19, 36-50 (1944)

47. Bockris, J.O., Parry-Jones, R.: Determination of the relative electrode potential of an uncharged metal in solution. Nature 171, 930-931 (1953)

48. Clark, R.E.D.: The influence of electric potentials upon friction. Part I.-In aqueous solutions of salts. Trans. Faraday Soc. 42, 449-456 (1946)

49. Hickling, A.: Studies in electrode polarisation. Part IV. The automatic control of the potential of a working electrode. Trans. Faraday Soc. 38, 27-33 (1942)

50. Bowden, F.P., Young, L.: Influence of interfacial potential on friction and surface damage. Research 3, 235-237 (1950)

51. Staicopolus, D.N.: "Electrocapillary" studies on solid metals. J. Electrochem. Soc. 108, 900-904 (1961). https://doi. org/10.1149/1.2428246

52. Bockris, J.O., Argade, S.D.: Dependence of friction at wet contacts upon interfacial potential. J. Chem. Phys. 50, 1622-1623 (1969). https://doi.org/10.1063/1.1671249

53. Bockris, J.O., Sen, R.K.: Variation of the coefficient of friction with potential for a solid-solution contact: a revised calculation. Surf. Sci. 30, 237-241 (1972)

54. Bockris, J.O.M., Argade, S.D., Gileadi, E.: The determination of the potential of zero charge on solid metals. Electrochim. Acta. 14, 1259-1283 (1969). https://doi.org/10.1016/00134686(69)87021-0

55. Dubois, J.E., Lacaze, P.C., Courtel, R., Herrmann, C.C., Maugis, D.: Polaromicrotribometry: a friction method for the study of polarized metal solution interfaces: application to the gold electrode. J. Electrochem. Soc. 122, 1454-1460 (1975). https:// doi.org/10.1149/1.2134041

56. Cole, R.R.: An experimental investigation of the electrolytic grinding process. J. Manuf. Sci. Eng. Trans. ASME. 83, 194201 (1961). https://doi.org/10.1115/1.3664459

57. Meleka, A.H., Glew, D.A.: Electrochemical machining. Int. Met. Rev. 22, 229-252 (1977)

58. El-Raghy, S.M., Abd-El-Kader, Abou-El-Hassan, M.E.: Electrochemistry of abrasion corrosion of low alloy steel in $1 \% \mathrm{NaCl}$ solution. Corrosion. 40, 60-61 (1984). https://doi. org/10.5006/1.3593916

59. Abd-El-Kader, H., El-Raghy, S.M.: Wear-corrosion mechanism of stainless steel in chloride media. Corros. Sci. 26, 647-653 (1986). https://doi.org/10.1016/0010-938X(86)90029-6 
60. Naerheim, Y., Kendig, M.W.: The influence of electrochemical potential on wear. Wear 104, 139-150 (1985). https://doi. org/10.1016/0043-1648(85)90058-4

61. Pearson, B.R., Brook, P.A., Waterhouse, R.: Influence of electrochemical potential on the wear of metals, particularly nickel. Tribol. Int. 21, 191-197 (1988)

62. Brandon, N.P., Bonanos, N., Fogarty, P.O., Mahmood, M.N.: The effect of interfacial potential on friction in a model aqueous lubricant. J. Electrochem. Soc. (1992). https://doi. org/10.1149/1.2069104

63. Kelsall, G.H., Zhu, Y., Spikes, H.A.: Electrochemical effects on friction between metal oxide surfaces in aqueous solutions. J. Chem. Soc. Faraday Trans. 89, 267-272 (1993). https://doi. org/10.1039/FT9938900267

64. Zhu, Y.Y., Kelsall, G.H., Spikes, H.A.: The influence of electrochemical potentials on the friction and wear of iron and iron oxides in aqueous systems. Tribol. Trans. 37, 811-819 (1994). https://doi.org/10.1080/10402009408983363

65. Kautek, W., Dieluweit, S., Sahre, M.: Combined scanning force microscopy and electrochemical quartz microbalance in-situ investigation of specific adsorption and phase change processes at the silver/halogenide interface. J. Phys. Chem. B. 101, 2709-2715 (1997). https://doi.org/10.1021/jp962724w

66. Endo, K., Fukuda, Y., Takamiya, O.: Wear behaviours of metals under lubricated conditions and the effects of small electric potential. Trans. Jpn. Soc. Mech. Eng. 14, 1281-1288 (1971)

67. Shor, G.I., Blagovidov, I., Eustigneev, E., Lapin, V.P.: Antiwear and antiscuff properties of lubricating oils in relation to electric potential at metal-oil phase boundary. Chem. Tech. Fuels Oil 8, 770-772 (1972)

68. Shor, G.I., Evstigneev, E.V.: Effect of electric fields on the wear of metals in mineral oils with additives. Mater. Sci. 5, 457-460 (1972)

69. Katafuchi, T.: Effects of electric current on wear under lubricated condition. 1 Electric current-wear characteristics (in Japanese). J. Japan Soc. Lubr. Eng. 30, 883-886 (1985)

70. Katafuchi, T.: Effects of electric current on wear under lubricated condition 2. Effects on addition of additives on current (In Japanese). J. Jpn. Soc. Lubr. Eng. 30, 887-893 (1985)

71. Morizur, M.F., Briant, J.: Modifications of electron properties of friction surfaces in boundary lubrication. In: Proc. I. Mech. E. International Conference Tribology-Friction, Lubrication and Wear Fifty Years On. Volume 1, C214/87, pp. 447-454 (1987)

72. Takeuchi, A., Sato, M., Aoki, H.: Effect of applied voltage on friction characteristics under mixed lubrication conditions. J. Jpn. Soc. Lubr. Eng. 9, 45-46 (1988)

73. Yamamoto, Y., Yagi, J., Higaki, H.: Effect of electric field applied on friction and wear characteristics. JSME Intern. J. Ser. III(35), 641-646 (1992)

74. Gangopadhyay, A., Paputa Peck, M.C., Simko, S.J.: Wear control in a lubricated contact through externally applied electric current. Tribol. Trans. 45, 302-309 (2002). https://doi.org/10.1080/10402 000208982553

75. Wang, S.S., Maheswari, S.P., Yar-Ming, W., Tung, S.C.: An electrochemical technique for characterizing metal-lubricant interfacial reactions. ASLE Trans. 30, 394-402 (1987). https:// doi.org/10.1080/05698198708981772

76. Wang, S.S., Tung, S.C.: Using electrochemical and spectroscopic techniques as probes for investigating metal-lubricant interactions. Tribol. Trans. 33, 503-571 (1990). https://doi. org/10.1080/10402009008981990

77. Tung, S.C., Wang, S.S.: Friction reduction from electrochemically deposited films. Tribol. Trans. 34, 23-34 (1991). https:// doi.org/10.1080/10402009108982005
78. Tung, S.C., Wang, S.S.: In-situ electro-charging for friction reduction and wear resistant film formation. Tribol. Trans. 34, 479-488 (1991). https://doi.org/10.1080/10402009108982060

79. Wang, S.S., Lee, H.S.: The development of in situ electrochemical oil-condition sensors. Sens. Actuators B 17, 179-185 (1994). https://doi.org/10.1016/0925-4005(93)00867-X

80. Bond, A.M., Mann, T.F.: Voltammetric measurements without ohmic and other forms of distortion in aromatic hydrocarbon solvents. Electrochim. Acta 32, 863-870 (1987). https://doi. org/10.1016/0013-4686(87)87075-5

81. Blankespoor, R.L.: Electrochemical oxidation of zinc bis $(\mathrm{O}$, O-dialkyl phosphorodithioates-S, S'). Mediation by 1,1 ' -Bis(methoxycarbonyl)ferrocene. Inorg. Chem. 24, 1126-1128 (1985). https://doi.org/10.1021/ic00202a003

82. Stezeryanskii, E.A., Litovchenko, K.I., Kublanovsky, V.S.: Electro-oxidation of zinc diisooctyldithiophosphate. J. Electroanal. Chem. 390, 143-145 (1995). https://doi.org/10.1016/00220728(95)03893-L

83. Ozimina, D.: The assessment of ZnDTP tribochemical reactivity by electrochemical simulation. Lubr. Sci. 13, 45-57 (2000)

84. Xu, X., Brandon, N., Spikes, H.: Study of zinc dialkyldithiophosphate using electrochemical techniques. In: Proc. Leeds-Lyon Symp. Boundary and Mixed Lubrication, Vienna Sept. 2001, pp. 175-181 (2001)

85. Brandon, N.P., Bonanos, N., Fogarty, P.O., Mahmood, M.N., Moore, A.J., Wood, R.J.K.: Influence of potential on the friction and wear of mild steel in a model aqueous lubricant. J. Appl. Electrochem. 23, 456-462 (1993). https://doi.org/10.1007/BF007 07622

86. Meng, Y., Hu, B., Chang, Q.: Control of local friction of metal/ ceramic contacts in aqueous solutions with an electrochemical method. Wear 260, 305-309 (2006). https://doi.org/10.1016/j. wear.2005.03.036

87. He, S., Meng, Y., Tian, Y., Zuo, Y.: Response characteristics of the potential-controlled friction of $\mathrm{ZrO} 2 /$ stainless steel tribopairs in sodium dodecyl sulfate aqueous solutions. Tribol. Lett. 38, 169-178 (2010). https://doi.org/10.1007/s11249-010-9587-3

88. He, S., Meng, Y., Tian, Y.: Correlation between adsorption/ desorption of surfactant and change in friction of stainless steel in aqueous solutions under different electrode potentials. Tribol. Lett. 41, 485-494 (2011). https://doi.org/10.1007/s1124 9-010-9604-6

89. Cao, H., Meng, Y.: Electrochemical effect on boundary lubrication of ZDDP additive blended in propylene carbonate / diethyl succinate. Tribol. Int. 126, 229-239 (2018). https://doi. org/10.1016/j.triboint.2018.05.025

90. Xie, G., Luo, J., Liu, S., Guo, D., Zhang, C.: Nanoconfined liquid aliphatic compounds under external electric fields: roles of headgroup and alkyl chain length. Soft Matter 7, 4453-4460 (2011). https://doi.org/10.1039/c0sm00971g

91. Nielinger, M., Baltruschat, H.: Nanotribology under electrochemical conditions: influence of a copper (sub)monolayer deposited on single crystal electrodes on friction forces studied with atomic force microscopy. Phys. Chem. Chem. Phys. 9, 3965-3969 (2007). https://doi.org/10.1039/b706804b

92. Labuda, A., Paul, W., Pietrobon, B., Lennox, R.B., Grütter, P.H., Bennewitz, R.: High-resolution friction force microscopy under electrochemical control. Rev. Sci. Instrum. (2010). https://doi. org/10.1063/1.3470107

93. Hausen, F., Gosvami, N.N., Bennewitz, R.: Anion adsorption

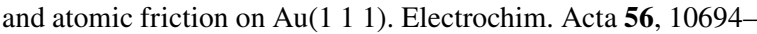
10700 (2011). https://doi.org/10.1016/j.electacta.2011.03.013

94. Labuda, A., Hausen, F., Gosvami, N.N., Grütter, P.H., Lennox, R.B., Bennewitz, R.: Switching atomic friction by electrochemical oxidation. Langmuir 27, 2561-2566 (2011). https://doi. org/10.1021/la104497t 
95. Zhang, J., Meng, Y., Yu, X.: Control of friction distribution on stainless steel surface in sodium dodecyl sulfate aqueous solution by bipolar electrochemistry. Tribol. Lett. 59, 1-8 (2015). https:// doi.org/10.1007/s11249-015-0571-9

96. Mavre, F., Anand, R.K., Laws, D.R., Chow, K., Chang, B., Crooks, J.A., Crooks, R.M.: Bipolar electrodes : a useful tool for concentration, separation, and detection of analytes in microelectrochemical systems. Anal. Chem. 82, 8766-8774 (2010). https://doi.org/10.1021/ac101262v

97. Dold, C., Amann, T., Kailer, A.: sliding contacts lubricated by an ionic liquid. Phys. Chem. Chem. Phys. 17, 10339-10342 (2015). https://doi.org/10.1039/c4cp05965d

98. Yang, X., Meng, Y., Tian, Y.: Effect of imidazolium ionic liquid additives on lubrication performance of propylene carbonate under different electrical potentials. Tribol. Lett. 56, 161-169 (2014). https://doi.org/10.1007/s11249-014-0394-0

99. Yang, X., Meng, Y., Tian, Y.: Controllable friction and wear of nitrided steel under the lubrication of [DMIm]PF6/PC solution via electrochemical potential. Wear 360-361, 104-113 (2016). https://doi.org/10.1016/j.wear.2016.04.010

100. Sweeney, J., Hausen, F., Hayes, R., Webber, G.B., Endres, F., Rutland, M.W., Bennewitz, R., Atkin, R.: Control of nanoscale friction on gold in an ionic liquid by a potential-dependent ionic lubricant layer. Phys. Rev. Lett. 109, 1-5 (2012). https://doi. org/10.1103/PhysRevLett.109.155502

101. Li, H., Rutland, M.W., Atkin, R.: Ionic liquid lubrication: Influence of ion structure, surface potential and sliding velocity. Phys. Chem. Chem. Phys. 15, 14616-14623 (2013). https://doi. org/10.1039/c3cp52638k

102. Li, H., Wood, R.J., Endres, F., Atkin, R.: Influence of alkyl chain length and anion species on ionic liquid structure at the graphite interface as a function of applied potential. J. Phys. Condens. Matter. 26, 284115 (2014). https://doi.org/10.1088/0953$8984 / 26 / 28 / 284115$

103. Li, H., Wood, R.J., Rutland, M.W., Atkin, R.: An ionic liquid lubricant enables superlubricity to be "switched on" in situ using an electrical potential. Chem. Commun. 50, 4368-4370 (2014). https://doi.org/10.1039/c4cc00979g

104. Li, H., Cooper, P.K., Somers, A.E., Rutland, M.W., Howlett, P.C., Forsyth, M., Atkin, R.: Ionic liquid adsorption and nanotribology at the silica-oil interface: Hundred-fold dilution in oil lubricates as effectively as the pure ionic liquid. J. Phys. Chem. Lett. 5, 4095-4099 (2014). https://doi.org/10.1021/jz5021422

105. Cooper, P.K., Li, H., Rutland, M.W., Webber, G.B., Atkin, R.: Tribotronic control of friction in oil-based lubricants with ionic liquid additives. Phys. Chem. Chem. Phys. 18, 23657-23662 (2016). https://doi.org/10.1039/c6cp04405k

106. Ma, X., Shrotriya, P.: Molecular dynamics simulation of electrical field induced conformational transition and associated frictional performance of monomolecular films. J. Phys. D 45, 375306 (2012). https://doi.org/10.1088/0022-3727/45/37/37530 6

107. Manzato, C., Foster, A.S., Alava, M.J., Laurson, L.: Friction control with nematic lubricants via external fields. Phys. Rev. E 91, 1-6 (2015). https://doi.org/10.1103/PhysRevE.91.012504

108. Fajardo, O.Y., Bresme, F., Kornyshev, A.A., Urbakh, M.: Electrotunable friction with ionic liquid lubricants: How important is the molecular structure of the ions? J. Phys. Chem. Lett. 6, 3998-4004 (2015). https://doi.org/10.1021/acs.jpclett.5b01802

109. Rehbinder, P.: New physico-chemical phenomena in the deformation and mechanical treatment of solids. Nature 159, 866-867 (1947)

110. Andrade, E.N.C., Randall, R.F.Y.: The Rehbinder effect. Nature 164(4183), 1127 (1949)

111. Kramer, I.R., Demer, L.J.: Effects of environment on mechanical properties of metals. Prog. Mater. Sci. 9, 133-199 (1961)
112. Westwood, A.R.C., Lockwood, F.E.: Chemomechanical effects in Lubrication. In: Tribology Series, vol. 7, pp. 421-447. Elsevier (1981)

113. Bowden, F.P., Hughes, T.P.: The friction of clean metals and the influence of adsorbed gases. The temperature coefficient of friction. Proc. R. Soc. Lond. Ser. A 172, 263-279 (1939). https ://doi.org/10.1098/rspa.1939.0103

114. Liu, C., Friedman, O., Li, Y., Li, S., Tian, Y., Golan, Y., Meng, Y.: Electric response of $\mathrm{CuS}$ nanoparticle lubricant additives : the effect of crystalline and amorphous octadecylamine surfactant capping layers. Langmuir 35, 15825-15833 (2019). https://doi. org/10.1021/acs.langmuir.9b01714

115. Liu, C., Meng, Y., Tian, Y.: Potential—controlled boundary lubrication using-MoS2 additives in diethyl succinate. Tribol. Lett. 68(72), 1-14 (2020). https://doi.org/10.1007/s11249-02001313-w

116. Kimura, Y., Nakano, K., Kato, T., Morishita, S.: Control of friction coefficient by applying electric fields across liquid crystal boundary films. Wear 175, 143-149 (1994). https://doi. org/10.1016/0043-1648(94)90177-5

117. Drummond, C.: Electric-field-induced friction reduction and control. Phys. Rev. Lett. 109, 1-5 (2012). https://doi.org/10.1103/ PhysRevLett.109.154302

118. Pashazanusi, L., Oguntoye, M., Oak, S., Albert, J.N.L., Pratt, L.R., Pesika, N.S.: Anomalous potential-dependent friction on $\mathrm{Au}(111)$ measured by AFM. Langmuir 34, 801-806 (2018). https ://doi.org/10.1021/acs.langmuir.7b03023

119. Li, S., Bai, P., Li, Y., Chen, C., Meng, Y., Tian, Y.: Electric potential-controlled interfacial interaction between gold and hydrophilic / hydrophobic surfaces in aqueous solutions. J Phys Chem C. 122, 22549-22555 (2018). https://doi.org/10.1021/acs. jpcc. 8 b06755

120. Su, Y.Y.: Electrochemical study of the interaction between fatty acid and oxidized copper. Tribol. Int. 30, 423-428 (1997). https ://doi.org/10.1016/S0301-679X(97)00005-4

121. Su, Y.Y.: Enhanced boundary lubrication by potential control during copper wire drawing. Wear 210, 165-170 (1997). https:// doi.org/10.1016/S0043-1648(97)00057-4

122. Nakayama, K., Hashimoto, H.: Triboemission from various materials in atmosphere. Wear 147, 335-343 (1991). https://doi. org/10.1016/0043-1648(91)90190-6

123. Nakayama, K.: Triboemission of charged particles from various solids under boundary lubrication conditions. Wear 178, 61-67 (1994). https://doi.org/10.1016/0043-1648(94)90129-5

124. McFadden, C., Hughes, K., Raser, L., Newcomb, T.: Electrical conductivity of new and used automatic transmission fluids. SAE Int. J. Fuels Lubr. 9, 519-526 (2016). https://doi. org/10.4271/2016-01-2205

125. Abedian, B., Baker, K.N.: Temperature effects on the electrical conductivity of dielectric liquids. IEEE Trans. Dielectr. Electr. Insul. 15, 888-892 (2008). https://doi.org/10.1109/ TDEI.2008.4543127

126. Tang, T.H.Z., Devlin, M., Mathur, N., Henly, T., Saathoff, L.: Lubricants for (hybrid) electric transmissions. SAE Tech. Pap. 2, 289-294 (2013). https://doi.org/10.4271/2013-01-0298

127. $\mathrm{Xu}, \mathrm{X}$. : Application of electrochemical techniques to tribology. $\mathrm{PhD}$ thesis, University of London (2004)

128. Xu, X., Spikes, H., Brandon, N.: New electrolytes for electrochemical study in hydrocarbon solution. In: Bhushan, B. (ed.) Proceedings of NATO Course, Keszthely, Hungary, August 2000, Fundamentals of Tribology - Bridging the Gap between Macro- Micro/ and Nanoscales, pp. 663-689. Kluwer Acad. Publ. Dordrecht (2001)

129. Briscoe, B.J., Evans, D.C.B., Tabor, D.: The influence of contact pressure and saponification on the sliding behavior of stearic acid 
monolayers. J. Colloid Interface Sci. 61, 9-13 (1977). https://doi. org/10.1016/0021-9797(77)90411-8

130. Spikes, H.A., Ogano, S., Ratoi, M., Kelsall, G.: Film thickness and friction properties of oiliness additives. In: Proceedings of International Tribology Conference, Nagasaki 2000, Satellite Forum Tribochemistry Tsukuba 2000, pp. 37-44 (2000)

131. Cole, R.R.: Basic research in electrochemical machiningpresent status and future directions. Int. J. Prod. Res. 4, 75-85 (1965). https://doi.org/10.1080/00207546508919966

132. Zhai, W.: Research progress in tribo-electrochemistry and triboelectrochemical polishing. Front. Mech. Eng. China. 2, 463-467 (2007). https://doi.org/10.1007/s11465-007-0080-0

133. Bandyopadhyay, B.P., Ohmori, H., Takahashi, I.: Efficient and stable grinding of ceramics by electrolytic in-process dressing (ELID). J. Mater. Process. Technol. 66, 18-24 (1997). https:// doi.org/10.1016/S0924-0136(96)02454-5

134. Lee, S.J., Lee, Y.M., Du, M.F.: The polishing mechanism of electrochemical mechanical polishing technology. J. Mater. Process. Technol. 140, 280-286 (2003). https://doi.org/10.1016/S0924 -0136(03)00720-9

135. Mckenzie, W.M., Hillis, W.E.: Evidence of chemical acceleration of wear in cutting plant materials. Wear 8, 238-243 (1965). https ://doi.org/10.1016/0043-1648(65)90162-6

136. Brandon, N.P., Wood, R.J.K.: The influence of interfacial potential on friction and wear in an aqueous drilling mud. Wear 170, 33-38 (1993). https://doi.org/10.1016/0043-1648(93)90348-P

137. Brandon, N.P., Panesar, S.S., Bonanos, N., Fogarty, P.O., Mahmood, M.N.: The effect of cathodic currents on friction and stuck pipe release in aqueous drilling muds. J. Pet. Sci. Eng. 10, 75-82 (1993). https://doi.org/10.1016/0920-4105(93)90032-A

138. Beard, J.: The best way to speed the plough? Plug it in. New Scientist Jan 22 (1994)

139. Kauffman, R.E.: Method for evaluating the remaining useful life of a lubricant. US Patent No, 4,744,870 (1988)

140. Kauffman, R.E.: Development of a remaining useful life of a lubricant evaluation techniques, Part III: cyclic voltammetric methods. Lubr. Eng. 45, 709-716 (1989)

141. Myle, B., Kauffman, R.E.: The use of cyclic voltammetric antioxidant analysis for proactive engine oil condition monitoring program. SAE Tech. Pap. (2000). https://doi. org/10.4271/2000-01-1810

142. ASTM International: ASTM D6810: Standard Test Method for Measurement of Hindered Phenolic Antioxidant Content in NonZinc Turbine Oils by Linear Sweep Voltammetry. ASTM Stand. D6810-13 (2013). https://doi.org/10.1520/D7527-10.2

143. ASTM International: ASTM D6971: Standard Test Method for Measurement of Hindered Phenolic Antioxidant Content in HL Turbine Oils by Linear Sweep Voltammetry 1. ASTM Stand. ASTM D6971 (2014). https://doi.org/10.1520/D7527-10.2

144. ASTM International: ASTM D7590: Standard Guide for Measurement of Remaining Primary Antioxidant Content In In-Service Industrial Lubricating Oils by Linear Sweep Voltammetry. ASME Stand. ASTM D7590 (2014). https://doi.org/10.1520/ D7590

145. Markova, L.V., Myshkin, N.K., Semenyuk, M.S., Makarenko, V.M., Kolesnikov, A.V., Hong, H., Han, H., Un, E.: Methods and means of diagnostics of working properties of a lubricating material. Trenie Iznos 24, 523-533 (2003)

146. Mujahid, A., Dickert, F.L.: Monitoring automotive oil degradation: analytical tools and onboard sensing technologies. Anal. Bioanal. Chem. 404, 1197-1209 (2012). https://doi. org/10.1007/s00216-012-6186-1

147. Zhu, J., He, D., Bechhoefer, E.: A survey of lubrication oil condition monitoring, diagnostics and prognostics techniques and systems. J. Chem. Sci. Techn. 2, 100-115 (2013)
148. Zhu, X., Zhong, C., Zhe, J.: Lubricating oil conditioning sensors for online machine health monitoring-a review. Tribol. Int. 109, 473-484 (2017). https://doi.org/10.1016/j.tribo int.2017.01.015

149. Hirthe, R.W., Brunson, A.M., Shtaida, V.E., Zou, L.Q., Joehler, C'J., Shachemeyer, S.: Method of determining the fluid condition of diesel engine lubeicant during real operation. US patent $6,844,745$ B1 (2005)

150. Kremer, F.: Dielectric spectroscopy-yesterday, today and tomorrow. J. Non. Cryst. Solids. 305, 1-9 (2002). https://doi. org/10.1016/S0022-3093(02)01083-9

151. Lizhi, H., Toyoda, K., Ihara, I.: Dielectric properties of edible oils and fatty acids as a function of frequency, temperature, moisture and composition. J. Food Eng. 88, 151-158 (2008). https:// doi.org/10.1016/j.jfoodeng.2007.12.035

152. Guan, L., Feng, X.L., Xiong, G.: Engine lubricating oil classification by SAE grade and source based on dielectric spectroscopy data. Anal. Chim. Acta 628, 117-120 (2008). https://doi. org/10.1016/j.aca.2008.09.004

153. Gong, Y., Guan, L., Feng, X., Wang, L., Yu, X.: In-situ lubricating oil condition sensoring method based on two-channel and differential dielectric spectroscopy combined with supervised hierarchical clustering analysis. Chemom. Intell. Lab. Syst. 158, 155-164 (2016). https://doi.org/10.1016/j.chemolab.2016.09.004

154. Wang, S.S., Lee, H.S.: The application of ac impedance technique for detecting glycol contamination in engine oil. Sens. Actuators B 40, 193-197 (1997). https://doi.org/10.1016/S0925 $-4005(97) 80261-4$

155. Dervos, C.T., Paraskevas, C.D., Skafidas, P., Vassiliou, P.: Dielectric characterization of power transformer oils as a diagnostic life prediction method. IEEE Electr. Insul. Mag. 21, 11-19 (2005). https://doi.org/10.1109/MEI.2005.1389266

156. Ulrich, C., Petersson, H., Sundgren, H., Björefors, F., KrantzRülcker, C.: Simultaneous estimation of soot and diesel contamination in engine oil using electrochemical impedance spectroscopy. Sens. Actuators B 127, 613-618 (2007). https://doi. org/10.1016/j.snb.2007.05.014

157. Hirthe, R.W., Hu, J., Koehler, C.J., Seitz, M.A., David Richard Sosnowski, R.M.J., Wooto, D.L., Brunson, A.M.: Fluid formulation evaluation and improvemnt utilizing broad spectrum impedance spectroscopy. US patent 7,078,910 B2 (2006)

158. Meitzler, A.H., Saloka, G..: Method and apparatus for sensing the condition of lubricating oil in an internal combustion engine. US Patent No. 4,733,556 (1988)

159. Schilowitz, A.M., Lira-Cantu, M.M., Song, L., Vann, W.D.: Method for analysis of a working fluid using impedance sepctroscopy. US patent 7,109,729 B2 (2006)

160. Pérez, A.T., Hadfield, M.: Low-cost oil quality sensor based on changes in complex permittivity. Sensors 11, 10675-10690 (2011). https://doi.org/10.3390/s111110675

161. Schoess, J.N.: Oil quality sensor system, method and apparatus. US patent 6,718,819 B2. (2004)

162. Raadnui, S., Kleesuwan, S.: Low-cost condition monitoring sensor for used oil analysis. Wear 259, 1502-1506 (2005). https:// doi.org/10.1016/j.wear.2004.11.009

163. Basu, A., Berndorfer, A., Buelna, C., Campbell, J., Ismail, K., Lin, Y., Rodriguez, L., Wang, S.S.: "Smart sensing" of oil degradation and oil level measurements in gasoline engines. SAE Tech. Pap. (2000). https://doi.org/10.4271/2000-01-1366

164. Niksa, A.J., Fousek, J.D.: MEMS-based sensor for lubricant analysis. US patent 7,541,004 B2. (2009)

165. Glavatskih, S., Höglund, E.: Tribotronics-Towards active tribology. Tribol. Int. 41, 934-939 (2008). https://doi.org/10.1016/j. triboint.2007.03.001

166. Fuller, M.L.S., Kasrai, M., Bancroft, G.M., Fyfe, K., Tan, K.H.: Solution decomposition of zinc dialkyl dithiophosphate and its 
effect on antiwear and thermal film formation studied by X-ray absorption spectroscopy. Tribol. Int. 31, 627-644 (1998). https ://doi.org/10.1016/S0301-679X(98)00084-X

167. Masuko, M., Ohkido, T., Suzuki, A., Ueno, T.: Fundamental study of changes in friction and wear characteristics due to ZnDTP deterioration in simulating engine oil degradation during use. In: Proc Leeds Lyon Symposium on Tribology, Transient Processes in Tribology. Tribology Series, Elsevier, pp. 359-366. Elsevier (2003)

168. Bruno, F., Dubois, J.E.: Polaromicrotribometric study of a hydrophobic polymer film on platinum electrode during Kolbe electrosynthesis in aqueous media. Electrochim. Acta. 17, 11611170 (1972). https://doi.org/10.1016/0013-4686(72)80001-X

169. Desbene- Monvernay, A., Dubois, J.E.: Polarotribometric (PMT) study of the electrochemical formation of polymer films on metallic surfaces: polyacrolein films. J. Electroanal. Chem. 89, 149-160 (1978)

170. Pham, M., Dubois, J., Lacaze, P.: Polaromicrotribometric (p.m.t.) study of polymer film formation: m-hydroxy-benzyl alcohol. J. Electroanal. Chem. 99, 331-340 (1979)

171. Volkov, A., Tourillon, G., Lacaze, P.C., Dubois, J.E.: Electrochemical polymerization of aromatic amines. IR, XPS and PMT study of thin film formation on a Pt electrode. J. Electroanal. Chem. 115, 279-291 (1980). https://doi.org/10.1016/S0022 $-0728(80) 80332-9$

172. Desbene-Monvernay, A., Dubois, J.-E., Lacaze, P.-C.: Oxidative electropolymeriza tion of N-vinylcarbazole. J. Electroanal. Chem. Interfacial Electrochem. 189, 51-63 (1985). https://doi. org/10.1016/0368-1874(85)85625-2

173. Burgess, I., Jeffrey, C.A., Cai, X., Szymanski, G., Galus, Z., Lipkowski, J.: Direct visualization of the potential-controlled transformation of hemimicellar aggregates of dodecyl sulfate into a condensed monolayer at the $\mathrm{Au}(111)$ electrode surface. Langmuir 15, 2607-2616 (1999). https://doi.org/10.1021/la981 $023 \mathrm{i}$

174. Retter, U.: One-dimensional nucleation-growth-collision in the formation of surface hemimicelles of amphiphiles. Langmuir 16, 7752-7756 (2000). https://doi.org/10.1021/la000526x

175. Sek, S., Chen, M., Brosseau, C.L., Lipkowski, J.: In situ STM study of potential-driven transitions in the film of a cationic surfactant adsorbed on a $\mathrm{Au}(111)$ electrode surface. Langmuir 23, 12529-12534 (2007). https://doi.org/10.1021/la702095a

176. Soares, D.M., Gomes, W.E., Tenan, M.A.: Sodium dodecyl sulfate adsorbed monolayers on gold electrodes. Langmuir 23, 4383-4388 (2007). https://doi.org/10.1021/la063508+

177. Xu, S., Chen, M., Cholewa, E., Szymanski, G., Lipkowski, J.: Electric-field-driven surface aggregation of a model zwitterionic surfactant. Langmuir 23, 6937-6946 (2007). https://doi. org/10.1021/la0701327

178. Chen, M., Burgess, I., Lipkowski, J.: Potential controlled surface aggregation of surfactants at electrode surfaces-a molecular view. Surf. Sci. 603, 1878-1891 (2009). https://doi. org/10.1016/j.susc.2008.09.048

179. Kawamura, M.: Electrical method to observe lubricant films under dynamic conditions (in Japanese). J. Japan Soc. Lubr. Eng. 24, 331-336 (1979)

180. Lord, J., Larsson, R.: Film-forming capability in rough surface EHL investigated using contact resistance. Tribol. Int. 41, 831838 (2008). https://doi.org/10.1016/j.triboint.2007.11.006

181. Guangteng, G., Olver, A., Spikes, H.: Contact resistance measurements in mixed lubrication. In: The Advanced Frontier of
Engineering Tribology, Proc. 1999 STLE/ASME H.S. Cheng Tribology Surveillance, pp. 64-71 (1999)

182. Clarke, A., Weeks, I.J.J., Evans, H.P., Snidle, R.W.: An investigation into mixed lubrication conditions using electrical contact resistance techniques. Tribol. Int. 93, 709-716 (2016). https:// doi.org/10.1016/j.triboint.2014.10.010

183. Prajapati, D.K., Tiwari, M.: Investigation on metallic contact conditions using ECR technique by performing rolling/sliding experiments. Surf. Topogr. Metrol. Prop. (2019). https://doi. org/10.1088/2051-672X/ab042e

184. Palacios, J.M.: Elastohydrodynamic films in mixed lubrication: an experimental investigation. Wear 89, 303-312 (1983). https ://doi.org/10.1016/0043-1648(83)90151-5

185. Horng, J.H.: Studies of tribological behavior and separation between surfaces at initial boundary lubrication. Wear 216, 8-14 (1998). https://doi.org/10.1016/S0043-1648(97)00294-9

186. Lugt, P.M., Severt, R.W.M., Fogelström, J., Tripp, J.H.: Influence of surface topography on friction, film breakdown and runningin in the mixed lubrication regime. Proc. Inst. Mech. Eng. Part J 215, 519-533 (2001). https://doi.org/10.1243/135065001154377 2

187. Minami, I.: Ionic liquids in tribology. Molecules 14, 2286-2305 (2009). https://doi.org/10.3390/molecules14062286

188. Bermúdez, M.D., Jiménez, A.E., Sanes, J., Carrión, F.J.: Ionic liquids as advanced lubricant fluids. Molecules 14, 2888-2908 (2009). https://doi.org/10.3390/molecules 14082888

189. Zhou, Y., Qu, J.: Ionic liquids as lubricant additives: a review. ACS Appl. Mater. Interfaces. 9, 3209-3222 (2017). https://doi. org/10.1021/acsami.6b12489

190. MacFarlane, D.R., Forsyth, M., Izgorodina, E.I., Abbott, A.P., Annat, G., Fraser, K.: On the concept of ionicity in ionic liquids. Phys. Chem. Chem. Phys. 11, 4962-4967 (2009). https://doi. org/10.1039/b900201d

191. Pinkert, A., Ang, K.L., Marsh, K.N., Pang, S.: Density, viscosity and electrical conductivity of protic alkanolammonium ionic liquids. Phys. Chem. Chem. Phys. 13, 5136-5143 (2011). https ://doi.org/10.1039/c0cp02222e

192. Somers, A.E., Khemchandani, B., Howlett, P.C., Sun, J., Macfarlane, D.R., Forsyth, M.: Ionic liquids as antiwear additives in base oils: Influence of structure on miscibility and antiwear performance for steel on aluminum. ACS Appl. Mater. Interfaces. 5, 11544-11553 (2013). https://doi.org/10.1021/am4037614

193. Spikes, H.A.: Wear and fatigue problems in connection with water-based hydraulic fluids. J. Synth. Lubr. 4, 115-135 (1987). https://doi.org/10.1002/jsl.3000040203

194. Yilmaz, M., Lohner, T., Michaelis, K., Stahl, K.: Minimizing gear friction with water-containing gear fluids. Forsch. im Ingenieurwesen/Engineering Res. 83, 327-337 (2019). https://doi. org/10.1007/s10010-019-00373-2

195. Sagraloff, N., Dobler, A., Tobie, T., Stahl, K., Ostrowski, J.: Development of an oil free water-based lubricant for gear applications. Lubricants 7, 6-8 (2019). https://doi.org/10.3390/lubri cants7040033

196. Klüber Lubrication: Hydro-lubricants, https://www.klueber.com/ en/lubricants/hydro-lubricants/

Publisher's Note Springer Nature remains neutral with regard to jurisdictional claims in published maps and institutional affiliations. 